\title{
SLOW PROFILE: ESTUDO DAS ORIENTAÇÕES AO CONSUMO DE SLOW FASHION
}

\author{
Érica Maria Calíope Sobreira ${ }^{1}$, Clayton Robson Moreira da Silva, Cláudia Buhamra Abreu Romero \\ Universidade Federal do Paraná - UFPR, Curitiba, PR (Brasil) \\ Instituto Federal de Educação, Ciência e Tecnologia do Piauí - IFPI, Pedro II, PI (Brasil) \\ Universidade Federal do Ceará - UFC, Fortaleza, CE (Brasil)
}

\section{DETALHES DO ARTIGO}

\section{Article history:}

Recebido: 21 de dezembro de 2019

Aceito: 25 de Julho de 2020

Disponível online: 01 de Agosto de 2020

Double Blind Review System

\section{Scientific Editor}

Ilan Avrichir

\section{Key words}

Slow fashion

Orientações ao Consumo

Perfil do Consumidor

\begin{abstract}
RESUMO
Objetivo: Identificar perfis de orientação ao consumo de slow fashion, verificando os fatores associados aos diferentes perfis.

Método: Trata-se de uma pesquisa do tipo survey com 461 consumidores de vestuário do Estado do Ceará. Utilizou-se de um questionário com questões de perfil do respondente, além de uma seção dedicada à mensuração da orientação ao consumo de slow fashion, por meio da escala de Jung e Jin (2014). Foram utilizados métodos de análise descritiva, análise fatorial confirmatória (AFC), análise de cluster por k-means e análise de correspondência (ANACOR).

Principais Resultados: Os resultados indicam validade da escala no contexto desta pesquisa. Verificou-se a existência de três perfis de orientação: alta orientação, orientado à funcionalidade e averso à exclusividade. Observou-se que existe associação entre os diferentes perfis e as variáveis demográficas relacionadas à localização, renda, faixa etária, orientação sexual, escolaridade, estado civil e ocupação.

Relevância/originalidade: Estudos sobre slow fashion ainda carecem de informações sobre quem são os seus potenciais consumidores e quais são os seus perfis. Este estudo visa preencher esse gap da literatura. Esta pesquisa é relevante teoricamente por estudar o slow fashion e seus potenciais consumidores no Ceará e, do ponto de vista gerencial, pelo crescente número de marcas brasileiras e cearenses seguindo o conceito de slow fashion.

Contribuições teóricas/metodológicas: Como contribuição teórica, a validação da escala de Jung e Jin (2014) no contexto cearense, além de estender o corpo de conhecimento sobre perfis de potenciais consumidores de slow fashion.

Contribuições sociais / para a gestão (opcional): As implicações gerenciais dizem respeito ao fornecimento de informações que possam contribuir para o planejamento mercadológico e posicionamento de marca eficiente e direcionado a esses potenciais consumidores.
\end{abstract}

\section{Introdução}

A indústria da moda atual é insustentável devido aos seus impactos negativos para as pessoas e o meio ambiente (Choudhury, 2014). Comandada pelo sistema de fast fashion, esta indústria se baseia em respostas rápidas às tendências, estimulando a criação contínua de desejos por produtos com ciclos de vida curtos e de rápida obsolescência (Byun \& Sternquist, 2011; Niinimäki \& Hassi, 2011). Esse sistema, típico de lojas globalmente conhecidas como Zara, H\&M e Forever 21 (Levy \& Weitz, 2008), tem sido particularmente conhecido pelos danos ambientais ao longo da cadeia de suprimentos, além de escândalos relacionados à exploração de trabalhadores (Johansson, 2010). As devantagens do sistema vigente na indústria possibilitaram o depertar do interesse global no consumo de moda sustentável por meio do movimento slow fashion (Descatoires, 2017), que desenvolve uma compreensão abrangente de moda sustentável (Ertekin \& Atik, 2014). A moda lenta assume uma abordagem local, prezando pela transparência dos sistemas produtivos, pela valorização de produtores e do meio ambiente (Cline, 2012), e pelo desenvolvimento de produtos mais sustentáveis e sensoriais (Clark, 2008).

Derivado do movimento slow food, que tinha como objetivo de "combater" o fast food, o slow fashion adota princípios similares aos propostos na Itália por Carlo Petrini na década de 80 (Fletcher, 2008; Lee \& Ahn, 2015). O movimento slow cresceu e 
transcendeu o setor alimentar para alcançar outros setores, como o de vestuário. Dessa forma, pode-se dizer que o Slow Fashion, doravante denominada de $\mathrm{SF}$, "representa uma descontinuidade flagrante com as práticas do setor atual; uma ruptura com os valores e objetivos do fast fashion" (Fletcher, 2010, p. 262). Propõe desacelerar a moda e torná-la mais sustentável desde a produção de uma roupa até o final do seu ciclo de vida (Billeson \& Klasander, 2015). Portanto, funciona como forma de ativismo fashion (Ro \& Kim, 2011) e como solução prática para escapar dos problemas do fast fashion (Magnuson, Reimers \& Chao, 2017). A despeito dos vários enfoques atrelados à definição de slow fashion (e.g. movimento, ativismo fashion), neste estudo ele será entendido como um tipo de consumo de moda sustentável (Henninger, Alevizou, \& Oates, 2016).

Diferente da moda rápida, o slow fashion preconiza roupas de fabricação local, muitas vezes propiciando uma maior valorização de produtos advindos do artesanato local (Thomas, 2020). Além disso, são caracterizadas pela alta durabilidade, originadas a partir de materiais sustentáveis (Štefko \& Steffek, 2018), técnicas tradicionais de produção e do comércio justo (Fletcher, 2010). Assim, esse tipo de consumo pode propiciar o fortalecimento de conexões não só entre consumidores e suas peças bem como entre eles e os produtores de vestuário (Johansson, 2010). Para o consumidor slow fashion a noção de qualidade se sobrepõe a de quantidade (Jung \& Jin, 2016; Watson \& Yan, 2013), a ideia é consumir menos e melhor, sem que haja a preocupação com as tendências (Clark, 2008).

O slow fashion tem sido discutido no domínio da indústria têxtil e de vestuário como alternativa ao sistema vigente, além de bem recebido por consumidores mais conscientes de moda sustentável (Lee \& Ahn, 2015). As pesquisas empíricas sobre o tema cresceram nos últimos anos, apesar do estágio de desenvolvimento destes estudos ainda ser considerado inicial na literatura (Ertekin \& Atik, 2014; Legere \& Kang, 2020; Şener, Bişkin \& Kđlđnç, 2019). Em geral, tais estudos associam slow fashion com conceitos como fast fashion, sustentabilidade, responsabilidade social, consumo ético de vestuário (Magnuson, Reimers \& Chao, 2017; Pookulangara \& Shephard 2013). Além disso, propõem suas dimensões constituintes (Jung \& Jin, 2014) e como estas têm efeitos positivos sobre percepções de valor de produtos de moda lenta em países como Estados Unidos, Turquia e Cazaquistão (Jung \& Jun, 2016a;
Şener et al., 2019). Entretanto, os estudos sobre slow fashion ainda carecem de informações sobre quem são os seus potenciais consumidores e quais são os seus perfis (Jung \& Jin, 2016b), sobretudo em contextos da América Latina. Este estudo visa preencher esse gap da literatura, além de validar a escala de slow fashion proposta por Jung e Jin (2014) no contexto brasileiro.

A partir do exposto, o objetivo desta pesquisa é identificar perfis de orientação ao consumo de slow fashion, verificando os fatores associados aos diferentes perfis.

Pesquisas anteriores sobre slow fashion foram realizadas em países europeus, na Ásia (Hall, 2018), nos EUA e no Canadá (Overdiek, 2018). Na literatura recente, o único estudo que propõe explorar grupos de consumidores de slow fashion foi desenvolvido por Jung e Jin (2016b), trabalhando com uma amostra de 221 consumidores norte-americanos. Assim, esta pesquisa é relevante teoricamente, em primeiro lugar, por trazer o estudo do slow fashion e de seus potenciais consumidores para o Brasil, um país da América do Sul. O consumidor brasileiro tem se mostrado mais consciente e sustentável, não comprando de empresas associadas ao trabalho escravo (65\%) ou ao uso de testes em animais (58\%), além de estar buscando reduzir seu impacto no meio ambiente atráves de mudanças nos hábitos de consumo (42\%), segundo pesquisa Nielsen (2019), realizada em 8.240 lares, contando com a participação de mais de 21 mil pessoas. Em segundo lugar, é relevante por propor validar a escala de orientação ao slow fashion, desenvolvida internacionalmente, agora no Brasil, especificamente no contexto cearense. Em especial, o perfil de consumidores da região Nordeste do país está mais consciente na hora de comprar e consumir, optando por marcas mais sustentáveis (Lugoe, 2019).

Este estudo se mostra relevante do ponto de vista gerencial pelo crescente número de marcas brasileiras seguindo o conceito de slow fashion (e.g. Doisélles, que produz peças em crochê e tricô, e Nicole Bustamante, marca que preza pela produção de peças exclusivas, produzidas à mão e em pequena quantidade, segundo Quevedo (2017)). Outros exemplos são as marcas cearenses Catarina Mina, com bolsas e roupas feitas artesanalmente à base de crochê (Carvalho, 2020), assim como Gabriela Fiuza, cujo foco está na tradição do crochê, e a Jô de Paula, uma marca de vestuário com cadeia produtiva 
responsável e justa que trabalha em parceria com artesãos cearenses sob a proposta de slow fashion (Magno, 2015, 2019). Nesse sentido, os produtos de moda associados ao artesanato e marcas locais cearenses (Pessoa \& Santos, 2016) têm se destacado no contexto da moda slow. Este estudo contribui para as empresas cearenses que seguem o conceito de moda slow por meio da identificação de perfis de potenciais consumidores orientados a esse tipo de consumo no Estado.

Ainda nesse contexto, o Estado do Ceará se destaca no cenário da moda devido à sua relevância para o faturamento da cadeia têxtil e de confecção nacional (ABIT, 2016). É notavelmente conhecido por sua forte relação com a moda autoral, o artesanato e a sustentabilidade na moda, sediando eventos como o Dragão Fashion, maior evento de moda autoral da América Latina (ABIT, 2019), e o Ceará Fashion Trade, feira de moda de Fortaleza, a capital do Estado, onde pequenas, médias e grandes empresas expõem os produtos típicos da moda cearense (Scaliotti, 2017). Nessa perspectiva, são vários os desafios de integrar o slow fashion às potencialidades do artesanato local, apesar de um segmento de consumidores mais conscientes estar disposto a abrir mão das roupas de fast fashion em prol das preocupações com questões de sustentabilidade (Cavalcante, 2019). Desse modo, esta pesquisa também fomenta a discussão sobre a possibilidade de internacionalização de produtos de slow fashion cearenses, visto que o mercado internacional ainda não tem um conceito formado sobre a imagem do Brasil no setor da moda (Sutter \& Maclennan, 2014), em especial para esse tipo de moda sustentável no Estado do Ceará.

Diante do exposto, este estudo opta por investigar as orientações ao consumo de slow fashion, com foco nos consumidores cearenses. A literatura sobre esse tipo de consumo será explorada na seção subsequente.

\section{Referencial teórico sobre Slow Fashion}

O slow fashion difere da moda sustentável, uma vez que o conceito desta representa e engloba "uma variedade de meios pelos quais um item ou comportamento de moda pode ser percebido como mais sustentável, incluindo (mas não limitado a) práticas ambientais, sociais, de slow fashion, de reutilização, de reciclagem, livre de crueldade, de anticonsumo, e de práticas de produção" (Mukendi et al., 2020, p. 2). Desse modo, embora esses termos normalmente venham sendo usados como sinônimos, eles têm conotações bastante diferentes, fazendo o conceito de slow fashion melhor se adequar à definição fornecida por Henninger et al. (2016), isto é, como um tipo de consumo de moda sustentável. Assim, entendido como um mercado de desobediência à moda rápida, dominante na indústria de vestuário, o slow fashion traz uma proposta de moda sustentável baseada em coleções ecológicas e éticas (Antanavičintè \& Dobilaitè, 2015) que costumam ocorrer duas vezes no ano, para primavera/verão e outono/inverno (Pookulangara \& Shephard, 2013). Nesse sentido, Fletcher (2010, p. 262) sugere que o slow fashion representa "uma visão de sustentabilidade no setor de moda [...]". Engloba noções de consumo consciente (Ertekin \& Atik, 2014), uma vez que constitui uma mudança de mentalidade do consumidor, que passa a não responder mais ao consumismo e às tendências (Johansson, 2010).

O slow fashion é um contraponto às "coleções de roupas de baixo custo que imitam as atuais tendências da moda de luxo" (Joy et al., 2012, p. 273) advindas do fast fashion. Em sua perspectiva de sustentabilidade, existe a crítica à produção do sistema dominante na indústria, desacelerando os ciclos da moda e o hiperconsumo, além de valorizar o trabalho daqueles envolvidos no processo de produção de peças vinculadas à recursos locais e à produção artesanal (Thomas, 2020).

O processo de moda lenta se estende do varejista ao consumidor, passando por processos de design, produção e consumo, cada um enfatizando aspectos específicos. No design, a ênfase está em práticas sustentáveis ou ecológicas, verdes e éticas. Na produção, se concentra na qualidade, habilidade e trabalho experiente. Por fim, no consumo o foco é longevidade, o investimento e a educação do consumidor, visto que o slow fashion desafia os indivíduos a se tornarem mais conscientes na tomada de decisões de consumo de vestuário (Pookulangara \& Shephard 2013).

Neste sentido, o slow fashion se fundamenta em princípios como abordagem local, valorizando recursos materiais e trabalhadores locais; sistemas de produção transparentes, havendo menos intermediação entre produtores e consumidores, pois os últimos são considerados "co-produtores" dentro da cadeia de suprimentos (i.e. agentes responsáveis pelos impactos de suas decisões de 
consumo). Além disso, o desenvolvimento de produtos sensoriais, isto é, com apelo ao consumidor pela alta qualidade e conforto, e sustentáveis de alta qualidade e o encorajamento de um consumo mais responsável e, portanto, reduzido (Cataldi, Dickson \& Grover, 2010; Clark, 2008; Cline, 2012).

Uma mudança no consumo de roupas, de quantidade para qualidade, é um dos pontos-chave do slow fashion (Jung \& Jin, 2016b). Os consumidores mantêm itens por mais tempo, uma vez que compram roupas de maior qualidade e com um ciclo de vida maior (Clark, 2008), o que reduz o número de compras, a rotatividade de peças no guarda-roupa e sua frequência de descarte (Magnuson et al, 2017). Cline (2012) argumenta que os consumidores de moda lenta podem optar por roupas remodeladas, consertadas ou até mesmo fazer as próprias roupas. Isto é, o slow fashion também ocorre através de processos de reciclagem e reutilização de roupas existentes. Ademais, pode estar aliado à produção local e ao artesanato (Aakko \& Koskennurmi-Sivonen, 2013; Niinimäki \& Hassi, 2011; Pookulangara \& Shephard, 2013).

Nessa perpectiva, o artesanato faz parte da construção e expressão da cultura de determinada localidade. Isso se dá através de produtos sujeitos à processos de fabricação manual de peças únicas a partir de materiais e técnicas de cofecção específicas (Mazza, Ipiranga, \& Freitas, 2007). Essa aproximação do "local" é o que faz do slow fashion um tipo de consumo de moda baseado em produção de pequena escala, mais artesanal, e na ideia de pertencimento a um lugar atrelada aos produtos slow (Fletcher \& Grose, 2012). Hall (2018) põe em foco a perspectiva cultural e local associada ao consumo do quimono através das lentes do slow fashion. Afirma, nesse sentido, que o quimono se alinha com as características desse tipo de moda sustentável em termos de produção e consumo (e.g. produção em pequena escala, leva tempo para ser criado com alta qualidade e geralmente tem uma longa vida útil). No Ceará, por exemplo, foco desta pesquisa, a utilização do artesanato como matéria-prima típica da produção de vestuário local (Pessoa \& Santos, 2016) sugere uma aproximação cada vez maior com os produtos de moda slow.

As coleções de slow fashion em geral apresentam preço mais alto, ou seja, os consumidores se dispõem a pagar um preço premium por produtos slow (Štefko \& Steffek, 2018). Consumidores mais jovens tendem a optar por roupas mais baratas que seguem as tendências de moda. Em contrapartida, aqueles mais velhos geralmente preferem menos roupas, de maior qualidade, indicando uma atitude mais favorável desses consumidores em relação ao consumo de slow fashion (Bhardwaj \& Fairhurst, 2010). Quanto ao processo de decisão de compra, os consumidores de slow fashion optam por peças atemporais, de bom investimento (i.e. alta durabilidade) e caimento, busca de construção de guarda-roupa de acordo com estilo e versatilidade, além da compra de itens que não seguem as tendências (Watson \& Yan, 2013).

Estudos anteriores discutiram diferenças entre consumidores de slow fashion e de fast fashion (Watson \& Yan, 2013), identificaram motivações e barreiras para a adoção do slow fashion (Ertekin \& Atik, 2014), além das dimensões que o constituem (Jung \& Jin, 2014). Outros aplicaram princípios slow à criação de coleções (Antanavičintè \& Dobilaitè, 2015), exploraram percepções de produtos (Pookulangara \& Shephard, 2013) ou percepções de valor em relação a esse tipo de consumo (Jung \& Jin, 2016a; Şener et al., 2019).

Nesta perspectiva, Jung e Jin (2014) foram os primeiros a operacionalizar o estudo do slow fashion por meio do desenvolvimento de uma escala de orientações a esse tipo de consumo (Legere $\&$ Kang, 2020). A scala conta com cinco dimensões: equidade, autenticidade, funcionalidade, exclusividade e localismo. Os consumidores conscientes de práticas de trabalho justas ao comprar roupas e que se preocupam com produtores e o comércio justo se orientam para a dimensão equidade. A valorização do artesanato e outras formas de produção feita à mão são típicas de consumidores orientados para autenticidade. Consumidores preocupados com a versatilidade e durabilidade das roupas são orientados para a funcionalidade enquanto aqueles que valorizam roupas raras e exclusivas, de edição limitada, são para a exclusividade. Não só a preferência ao uso de materiais locais como marcas locais às marcas globais evidencia a orientação para o localismo. Nesse sentido, as características das orientações para o consumo de peças de slow fashion se aproximam de aspectos que Bandyopadhyay e Ray (2020) associaram ao posicionamento de uma marca de moda sustentável, como a autenticidade dos produtos e processos e aspectos locais e/ou tradicionais do produto, incluindo seu design. 
O estudo de Jung e Jin (2016b), realizado com norte-americanos, apresenta potenciais grupos de consumidores de slow fashion classificados de acordo com o seu nível de envolvimento com as dimensões: alto ou baixo envolvimento, convencional e exclusivamente orientado. O primeiro e o segundo ocorrem em relação à todas as dimensões, evidenciando alto ou baixo envolvimento com elas. Já - convencial manifesta mais características da dimensão funcionalidade, isto é, estes consumidores potenciais estão altamente envolvidos com a busca de um estilo simples e versátil de usar suas peças ao longo de várias temporadas, sem preocupações quanto a seguir as tendências de moda. Para este grupo, a exclusividade é de mínima importância. De modo contrário, o exclusivamente orientado dá mais importância à exclusividade enquanto as outras dimensões apresentam baixa importância (Tabela 1).

\section{Tabela 1}

Perfis de consumidores para mercados de slow fashion

\begin{tabular}{|c|c|c|c|c|}
\hline & $\begin{array}{c}\text { Alto } \\
\text { envolvimento }\end{array}$ & Convencional & $\begin{array}{c}\text { Orientado à } \\
\text { exclusividade }\end{array}$ & $\begin{array}{c}\text { Baixo } \\
\text { envolvimento }\end{array}$ \\
\hline Dimensões-chave & Todas (alto) & Funcionalidade & Exclusividade & Todas (baixo) \\
\hline $\begin{array}{l}\text { Compras de vestuário feitas em } \\
\text { marcas de fast fashion }\end{array}$ & $\begin{array}{l}25 \% \text { das } \\
\text { compras em fast } \\
\text { fashion }\end{array}$ & $\begin{array}{l}5 \% \text { das compras } \\
\text { em fast fashion }\end{array}$ & $\begin{array}{c}20 \% \text { das } \\
\text { compras em } \\
\text { fast fashion }\end{array}$ & $\begin{array}{c}8 \%-9 \% \text { das } \\
\text { compras em fast } \\
\text { fashion }\end{array}$ \\
\hline Relação fast x slow fashion & Complementar & $\begin{array}{c}\text { Tende mais ao } \\
\text { slow pela } \\
\text { funcionalidade; } \\
\text { Grupo que } \\
\text { menos compra } \\
\text { em fast fashion }\end{array}$ & $\begin{array}{c}\text { Não } \\
\text { explicitada }\end{array}$ & $\begin{array}{c}\text { Tende menos ao } \\
\text { slow; } 22^{\circ} \text { grupo } \\
\text { que menos } \\
\text { compra em fast } \\
\text { fashion }\end{array}$ \\
\hline $\begin{array}{l}\text { Extensão da intenção de } \\
\text { compra de slow fashion }\end{array}$ & Alta & Intermediária & Intermediária & Baixa \\
\hline $\begin{array}{l}\text { Extensão da intenção de preço } \\
\text { premium }\end{array}$ & Alta & Intermediária & Intermediária & Baixa \\
\hline Demografia* & $\begin{array}{l}\text { Média etária: } 41 \\
\text { anos }\end{array}$ & $\begin{array}{c}\text { Média etária: } 54 \\
\text { anos; Mulheres } \\
(62.5 \%)\end{array}$ & $\begin{array}{l}\text { Média etária: } \\
41 \text { anos }\end{array}$ & $\begin{array}{c}\text { Média etária: } 45 \\
\text { anos; Homens } \\
(67.86 \%)\end{array}$ \\
\hline
\end{tabular}

Fonte: Elaborada pelos autores a partir de Jung e Jin (2016). Nota: *Apenas diferenças significativas foram apresentadas.

Jung e Jin (2014; 2016b) são os primeiros e únicos autores a propor dimensões e uma classificação em grupos orientados ao slow fashion (Legere \& Kang, 2020). Pesquisas passadas não chegaram a propor outros agrupamentos de potenciais consumidores, apenas utilizaram as cinco orientações estabelecidas na literatura por Jung e Jin. A proposta de orientações ao SF das autoras, nesta pesquisa, é trazida para o contexto cultural brasileiro, o qual apresenta idiossincrasias próprias, além daquelas pertencentes aos potenciais consumidores de slow fashion cearenses, foco deste artigo.

Nessa perspectiva, na tabela 1, os grupos foram comparados seguindo os seguintes critérios: dimensões-chave identificadas, porcentagem de compras de vestuário feitas em marcas de fast fashion, extensão da intenção de compra de slow fashion, extensão da intenção de preço premium e variáveis demográficas. Vale ressaltar que o estudo de Jung e Jin (2016b) não se refere aos consumidores de slow fashion como aqueles que compram unicamente produtos slow, mas como indivíduos que podem comprar fast fashion, mesmo quando se revelam altamente orientados para a moda lenta.

Nesse sentido, o grupo de alto envolvimento apresenta alta dependência da moda rápida (i.e. realiza $25 \%$ do total de suas compras em marcas de fast fashion) embora apresente a mais alta orientação para o consumo de slow fashion (i.e. valorize todos os atributos SF) e para a intenção de compra desses produtos, estando disposto a pagar um preço premium. Isso sugere que, paradoxalmente, este grupo vê uma relação de complementariedade entre produtos fast e slow. O grupo convencional, em sua maioria composto por mulheres, é o que melhor se dequada à filosofia slow por meio da dimensão funcionalidade. Os consumidores deste grupo são mais suscetíveis a esse 
tipo de consumo por valorizarem um atributo específico de SF, além de apresentarem um nível de intenção de compra e disposição a pagar intermediário. Ao mesmo tempo, são os que menos compram produtos fast fashion. Por sua vez, o grupo orientado à exclusividade não apresentou uma relação explícita entre slow e fast fashion, somente a intenção intermediária de comprar produtos slow similar a do grupo convencional. No entanto, nele os gastos com compras em fast fashion são inferiores apenas ao grupo de alto envolvimento. Por fim, o grupo de baixo envolvimento é o que menos se aproxima do slow fashion, visto que é o menos envolvido com os atributos característicos desse tipo de consumo. Tal grupo é composto em sua maioria por homens e apresenta baixos níveis de compra em marcas de fast fashion como em intenção de compra e disposição a pagar um preço premium por produtos slow. Nesse caso, o sexo pode representar um fator capaz de explicar esse resultado, pois consumidores do sexo masculino em geral são menos envolvidos com a compra de vestuário e a moda dos que consumidoras do sexo feminino

Os resultados do estudo de Jung e Jiun (2016b) sugerem que a viabilidade do slow fashion em um sistema dominado pelo fast fashion pode estar associada à coexistência dos sistemas, em uma tendência de relação complementar para consumidores altamente envolvidos com a moda, seja ela sustentável ou não (i.e. identificada no perfil de alto envolvimento). Existem, ainda, outras tendências. Poderia ocorrer a busca de uma relação de minimização dos impactos negativos da moda mainstream, insustentável, por meio da opção pelo slow fashion orientada por aspectos funcionais (i.e. perfil convencional), ou pela exclusividade atrelada à produção e aquisição de peças slow (i.e. perfil orientado à exclusividade).

\section{Metodologia}

Nesta seção são apresentadas informações acerca da amostra da pesquisa e dos procedimentos de coleta e análise de dados utilizados.

\section{Amostra e coleta de Dados}

Este estudo teve como população-alvo consumidores de vestuário do Estado do Ceará. Tratou-se de uma pesquisa do tipo survey online, que, segundo Teixeira, Zamberlan e Rasia (2009), permite investigar construtos e temas específicos por meio da consulta de opinião pública. Compreende-se que esta estratégia de pesquisa é adequada para a condução deste estudo.

A fim de calcular o tamanho ideal da amostra, tomou-se como população do estudo o número de habitantes do Estado do Ceará, uma vez que a pesquisa teve como foco o consumidor cearense. $O$ Instituto de Pesquisa e Estratégia Econômica do Ceará [IPECE] (2017) estima que o Estado do Ceará conta com uma população de 9.020 .460 habitantes. Desse modo, o cálculo amostral tomou como base a população evidenciada pelo IPECE (2017), além de considerar erro amostral de $5 \%$ e grau de confiança de 95\%. Com base nos valores apresentados, verificou-se que uma amostra composta por 385 respondentes atenderia aos parâmetros estabelecidos. Após a aplicação dos questionários, foram efetivadas as participações de 461 respondentes, sendo, dessa forma, o erro igual $4,56 \%$.

A coleta de dados foi realizada com o auxílio do Google Forms e partiu de um procedimento de amostragem não-probilístico de coleta por conveniência, uma vez que os respondentes foram acessados tendo em vista sua disponibilidade de participar da pesquisa. Sugere-se que o uso da amostragem por conveniência é recomendado em pesquisas exploratórias (Churchill Jr. \& lacobucci, 2009), apresentando-se uma alternativa viável para o estudo em questão. A fim de identificar o local de residência do respondente, o questionário contou com uma pergunta filtro sobre a UF em que o mesmo residia. Desse modo, foram inseridos na amostra apenas aqueles que afirmaram residir no Estado do Ceará, foco deste estudo.

\section{Questionário}

Utilizou-se um questionário como instrumento de coleta de dados. A primeira parte do questionário foi dedicada à caracterização do perfil do respondente (10 questões). A segunda, elaborada de acordo com escala de Jung e Jin (2014) - Orientação do Consumidor ao Slow fashion (Consumer Orientations to Slow fashion - COSF), serviu para medir a orientação a esse tipo de consumo. A escala contou com 15 itens, divididos em cinco dimensões: (i) equidade; (ii) autenticidade; (iii) funcionalidade; (iv) localismo; e (v) exclusividade. Utilizou-se uma escala do tipo Likert de 7 pontos, onde "1=discordo totalmente" e "7=concordo totalmente". 


\section{Procedimentos de análise}

A fim de atender ao objetivo da pesquisa, foram utilizados métodos estatísticos de análise descritiva, análise fatorial confirmatória (AFC), análise de cluster por k-means, teste Tukey HDS e análise de correspondência (ANACOR). Foram utilizados os softwares SPSS 23 e AMOS 23 para realizar os procedimentos estatísticos. Além disso, com o auxílio do Microsoft Excel, os dados foram explorados a fim de identificar possíveis outliers, missing values e outras informações incompletas nos questionários. Após esta análise, permaneceram na amostra apenas as respostas que atenderam a estes requisitos. A fim de verificar se há common method bias nos dados analisados, recorreu-se ao teste de Harman de um fator (Podsakoff, MacKenzie, Lee \& Podsakoff, 2003). Por meio do teste de Harman, verificou-se que a variância total obtida pelo fator foi de $30,48 \%$, indicando que os dados não sofreram com o common method bias.

A fim de verificar a consistência da Escala de Orientação do Consumidor ao Slow fashion, recorreuse ao método de AFC, uma vez que este método possibilita o teste de medidas teóricas pré-existentes (Hair Jr. et al., 2009), como é o da escala utilizada neste estudo. Desse modo, a aplicação da AFC neste estudo possibilita verificar a validade da escala e a eficácia de sua utilização no contexto investigado. Destaca-se, ainda, que a AFC é uma técnica quantitativa que permite testar o quão bem um conjunto de variáveis representa determinados constructos (Hair Jr. et al., 2009).

Com base nas dimensões da Escala de Orientação do Consumidor ao Slow Fashion, conduziu-se a análise de cluster por k-means, a fim de identificar diferentes grupos quanto à orientação ao consumo de slow fashion. O objetivo da análise de cluster é agrupar um conjunto de objetos com base em suas semelhanças, mas também com base em suas diferenças em relação aos demais clusters (Bai, Liang \& Cao, 2020), além da classificação dos respondentes segundo as dimensões extraídas de uma escala (Fávero, Belfiore, Silva \& Chan, 2009). Neste modelo, os clusters são associados a coleções compactas de pontos que surgem em torno de um conjunto de centróides de cluster (Hofmeyr, 2020). Para identificar quais variáveis foram estatisticamente significantes na discriminação e segmentação dos clusters foi realizado um teste ANOVA, e, com o auxílio do teste Tukey, foi possível verificar as diferenças estatísticas das variáveis de seleção em relação aos diferentes clusters extraídos.

Após identificados dos clusters, recorreu-se ao método de análise de correspondência (ANACOR). A partir dele se verificou a associação entre as características dos indivíduos e os diferentes clusters de orientação ao consumo de slow fashion. Esse método visa analisar a associação entre variáveis categóricas por meio de um mapa perceptual. Permite, portanto, a realização de uma análise visual do nível de associação entre as variáveis, com base em suas posições no mapa (Fávero et al., 2009). Ressalta-se que a ANACOR é uma técnica de interdependência desenvolvida recentemente, que possibilita a análise da relação entre um conjunto de atributos não-métricos. Considerando que os pesquisadores adotam constantemente a prática de quantificar dados qualitativos em busca de verificar relações entre variáveis nominais, este método se difere das demais técnicas de interdependência por sua capacidade de acomodar dados não-métricos e relações não-lineares (Hair Jr. et al, 2009), tornando viável sua aplicação nesta pesquisa.

\section{Resultados e Discussão}

Nesta seção são apresentados os resultados da pesquisa e sua discussão. Desse modo, o perfil dos respondentes é apresentado inicialmente, em seguida a análise confirmatória da escala utilizada. Por fim, os perfis de orientação ao consumo de slow fashion e os fatores associados aos diferentes perfis obtidos.

\section{Perfil dos respondentes}

A amostra deste estudo foi descrita por meio de variáveis demográficas referentes ao gênero, localização, faixa etária, orientação sexual, escolaridade, estado civil, ocupação e dependentes. A partir disso, verifica-se que, em geral, a amostra foi composta por 461 respondentes, dos quais: 67,90\% identificam-se com o gênero feminino; $70,28 \%$ vivem na capital; e 62,04\% possuem renda de $\mathrm{R} \$ 2.000,00$. Além disso, observou-se grande volume de jovens $(41,00 \%)$ ou adultos jovens (33,19\%); a maioria dos respondentes se declara heterossexual $(83,08 \%)$ e está cursando ou concluiu o ensino superior (54,44\%). Ainda, observou-se preponderância de indivíduos solteiros $(73,10 \%)$, profissionais ativos no 
mercado de trabalho $(57,92 \%)$ e com dependentes $(63,77 \%)$.

\section{Escala de orientação ao consumo de slow fashion}

Em relação à orientação ao consumo de slow fashion, realizou-se uma AFC com os 15 itens da
Escala de Orientação do Consumidor ao Slow Fashion a fim de verificar sua validade para a utilização nesta pesquisa. A Figura 1 apresenta a estrutura geral do modelo de validação da escala, evidenciando os cinco constructos propostos e o conjunto de itens que compõe cada dimensão: equidade; autenticidade; funcionalidade; localismo; e exclusividade.

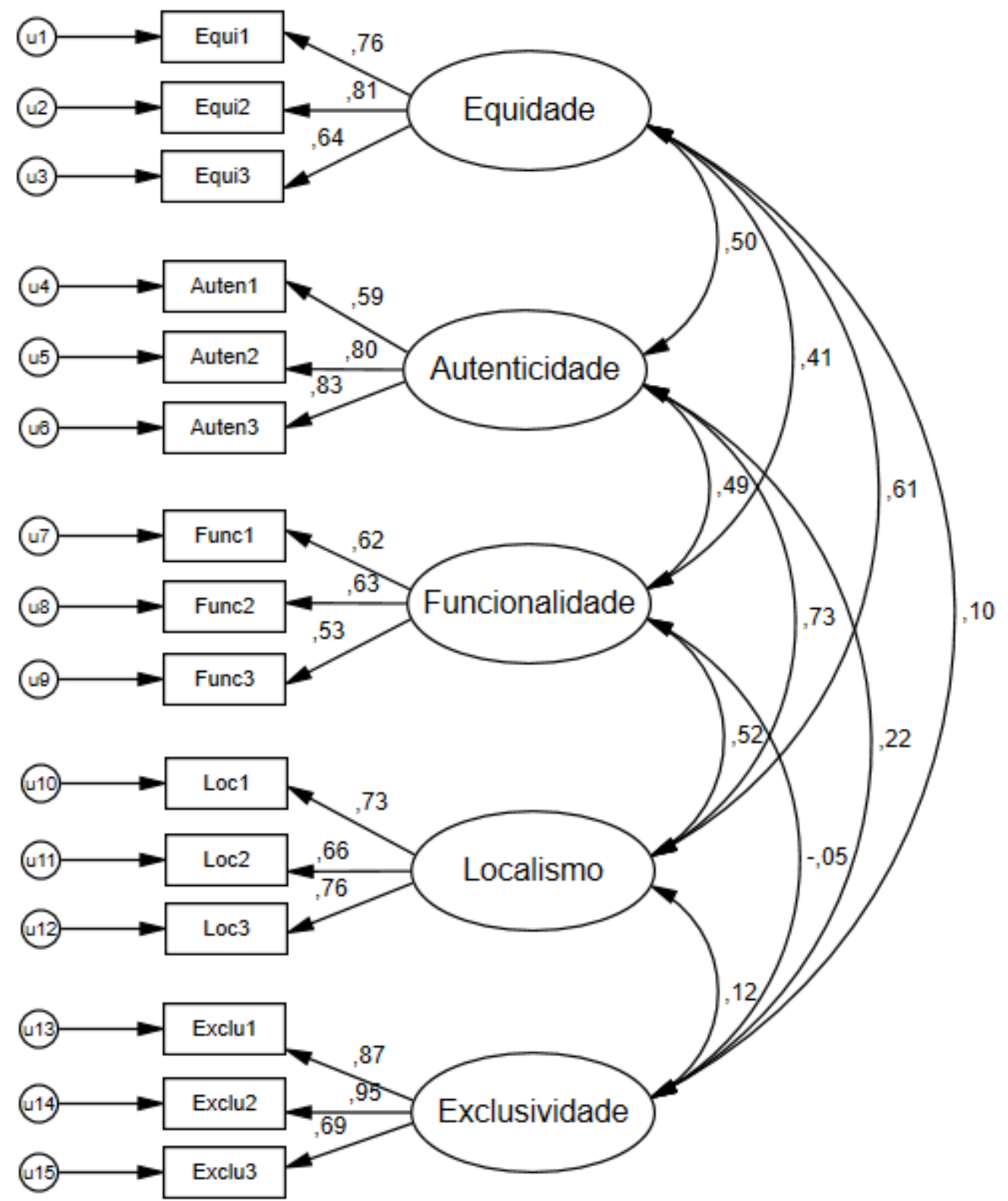

Figura 1. Estrutura geral da análise fatorial confirmatória.

Nota. Fonte: Dados da pesquisa.

Com base na Figura 1, verificou-se que as cargas fatoriais padronizadas foram superiores a $0,5 \mathrm{em}$ todos os itens, de todas as dimensões, indicando adequacação da proposta de Jung e Jin (2014), em que a orientação ao consumo de slow fashion é dividida em cinco dimensões. De forma mais detalhada, a Tabela 2 evidencia as estimações das cargas fatoriais padronizadas, o erro padronizado, a significância estatística da relação entre os itens e a variável latente, os valores de Validade Discriminante, do Alfa de Cronbach, e do coeficiente de Confiabilidade Composta para cada dimensão analisada. 
Tabela 2

Análise Fatorial Confirmatória da Escala de Orientação ao Consumo de Slow fashion

\begin{tabular}{|c|c|c|c|}
\hline & $\begin{array}{l}\text { Est. } \\
\text { Pad. }\end{array}$ & $\begin{array}{l}\text { Erro } \\
\text { Pad. }\end{array}$ & valor-p \\
\hline \multicolumn{4}{|l|}{ Equidade $(\alpha=0,773 ; \mathrm{CR}=0,781 ; \mathrm{AVE}=0,545)$} \\
\hline $\begin{array}{l}\text { Equi. 1: Eu me preocupo com as condições de trabalho daqueles que produzem as roupas } \\
\text { que eu compro. }\end{array}$ & 0,755 & - & - \\
\hline Equi. 2: Eu me preocupo com o fair trade (comércio justo) quando eu compro roupas. & 0,809 & 0,074 & $* * *$ \\
\hline $\begin{array}{l}\text { Equi. 3: Eu acho importante que aqueles que produzem as roupas que eu compro sejam } \\
\text { remunerados de forma justa. }\end{array}$ & 0,641 & 0,056 & $* * *$ \\
\hline \multicolumn{4}{|l|}{ Autenticidade $(\alpha=0,784 ; C R=0793 ; \mathrm{AVE}=0,565)$} \\
\hline Auten. 1: Roupas feitas à mão têm mais valor que roupas produzidas em massa. & 0,595 & - & - \\
\hline Auten. 2: O uso de artesanato em roupas é muito importante. & 0,803 & 0,112 & $* * *$ \\
\hline Auten. 3: Eu valorizo roupas feitas com uso de técnicas tradicionais de costura. & 0,835 & 0,122 & $* * *$ \\
\hline \multicolumn{4}{|l|}{ Funcionalidade $(\alpha=0,583 ; C R=0,619 ;$ AVE $=0,352)$} \\
\hline $\begin{array}{l}\text { Func. 1: Eu costumo manter as roupas pelo maior tempo possível em vez de descartá-las } \\
\text { rapidamente. }\end{array}$ & 0,615 & - & - \\
\hline Func. 2: Eu normalmente gosto de vestir as mesmas roupas de diferentes formas. & 0,634 & 0,209 & $* * *$ \\
\hline Func. 3: Eu prefiro roupas com designs simples e clássicos. & 0,526 & 0,155 & $* * *$ \\
\hline \multicolumn{4}{|l|}{ Localismo $(\alpha=0,757 ; \mathrm{CR}=0,757 ; \mathrm{AVE}=0,511)$} \\
\hline Loc. 1: Eu acredito que roupas feitas com uso de materiais locais tem mais valor. & 0,725 & - & - \\
\hline Loc. 2: Eu prefiro comprar roupas feitas no Brasil do que roupas estrangeiras. & 0,658 & 0,079 & $* * *$ \\
\hline Loc. 3: Precisamos apoiar marcas brasileiras de vestuário. & 0,757 & 0,072 & $* * *$ \\
\hline \multicolumn{4}{|l|}{ Exclusividade $(\alpha=0,869 ; \mathrm{CR}=0,877 ; \mathrm{AVE}=0,708)$} \\
\hline Exclu. 1: Roupas de edições limitadas têm um atrativo especial para mim. & 0,865 & - & - \\
\hline Exclu. 2 Eu me sinto muito atraído por itens de vestuário que são raros. & 0,945 & 0,051 & $* * *$ \\
\hline Exclu. 3 Eu gosto de ter roupas que os outros não têm. & 0,694 & 0,052 & $* * *$ \\
\hline
\end{tabular}

Nota. Base: 461 respondentes. Fonte: Dados da pesquisa.

Com base nos resultados do Alfa de Cronbach, observou-se valor superior a 0,5 em todas as dimensões, indicando confiabilidade interna dos itens que compõem a escala (George \& Mallery, 2003). A fim de se ter uma percepção sobre a validade da AFC aqui conduzida, a Tabela 3 apresenta os valores das medidas de ajuste. Por sua vez, na Tabela 4 são apresentadas as correlações das dimensões de orientação ao consumo de slow fashion.

\section{Tabela 3}

Medidas de ajuste da análise fatorial confirmatória

\begin{tabular}{l|c|r}
\hline Medidas de Ajuste & Valores Calculados & Valores de Referência \\
\hline$X^{2}$ & $258,49$ (valor $p<0,001)$ & $($ valor $p>0,05)$ \\
\hline Df & 80 & $\leq$ \\
\hline$X^{2} / \mathrm{df}$ & 3,23 & $>5$ \\
\hline GFI & 0,93 & $<0,90$ \\
\hline RMSEA & 0,07 & $>0,08$ \\
\hline AGFI & 0,90 & $>0,90$ \\
\hline CFI & 0,93 & $>0,90$ \\
\hline
\end{tabular}

Nota. Base: 461 respondentes. Fonte: Dados da pesquisa. Valores de referência com base em Hooper et al. (2008). 
Tabela 4

Correlações das dimensões de orientação ao consumo de slow fashion

\begin{tabular}{|c|c|c|c|c|c|}
\hline & Equidade & Autenticidade & Funcionalidade & Localismo & Exclusivi \\
\hline Equidade & 0,738 & & & & \\
\hline Autenticidade & $0,497 * * *$ & 0,752 & & & \\
\hline Funcionalidade & $0,408 * * *$ & $0,494 * * *$ & 0,594 & & \\
\hline Localismo & $0,613 * * *$ & $0,730 * * *$ & $0,525 * * *$ & 0,715 & \\
\hline Exclusividade & $0,102 *$ & $0,216 * * *$ & $-0,049$ & $0,116 * *$ & 0,841 \\
\hline
\end{tabular}

Nota. Os valores da diagonal dizem respeito à raiz quadrada da AVE. Base: 461 respondentes. Fonte: Dados da pesquisa. $* * *$ valor- $p<0,01, * *$ valor- $p<0,05 e^{*}$ valor- $p<0,10$.

Os resultados reportados na Tabela 3, em que foi possível observar os valores de referência sugeridos na literatura (Hooper, Coughlan \& Mullen, 2008) e os valores calculados no modelo, os seguintes resultados foram observados: $X^{2}=258,49$ (valor- $p=$ $0,000) ; X^{2} / d f=3,23 ; \mathrm{GFI}=0,93 ;$ RMSEA = 0,07; AGFI $=0,90 ; \mathrm{CFI}=0,93$. Esses valores, com exceção do $X^{2}$, indicam que o modelo apresentou ajuste satisfatório, obedecendo aos limites aceitáveis. Destaca-se que, embora o $X^{2}$ não tenha atendido aos parâmetros (valor-p > 0,05), isto não inviabiliza a utilização deste modelo, uma vez que o $X^{2}$ é sensível a amostras grandes (Hooper et al., 2008). Dessa forma, com base nos resultados da AFC e dos valores obtidos pelo Alfa de Cronbach, compreende-se que os resultados indicam validade e consistência interna da escala, denotando viabilidade da sua utilização neste estudo.

\section{Perfis de orientação ao consumo de slow fashion}

A fim de que fossem identificados perfis de orientação ao consumo de slow fashion, recorreu-se ao método de análise de cluster por k-means. Os clusters foram calculados em função das dimensões da Escala de Orientação do Consumidor ao Slow Fashion. Dessa forma, foram analisadas cinco dimensões: (i) equidade; (ii) autenticidade; (iii) funcionalidade; (iv) localismo; e (v) exclusividade.

No método k-means, usado no estudo para agrupar os respondentes de acordo com determinado conjunto de variáveis (Fávero et al., 2009), o número de clusters é definido pelo analista. A fim de decidir a quantidade de clusters utilizada, foram observadas as características dos clusters, bem como o teste ANOVA e o teste de Tukey HSD, a fim de verificar diferenças estatísticas entre os clusters encontrados, além de comparações com o estudo de Jung e Jin (2016), que também definiram clusters em relação aos perfis de orientação ao consumo de slow fashion. Após esta etapa de análise, optou-se pela composição de três clusters, conforme pode ser observado na Tabela 5.

\section{Tabela 5}

Clusters - perfis de orientação ao consumo de slow fashion

\begin{tabular}{|c|c|c|c|c|c|}
\hline \multirow[b]{2}{*}{ Dimensões } & \multirow{2}{*}{$\begin{array}{c}\text { Alta } \\
\text { Orientação } \\
\text { (cluster 1) }\end{array}$} & \multirow{2}{*}{$\begin{array}{c}\text { Orientado à } \\
\text { Funcionalidade } \\
\text { (cluster } 2 \text { ) }\end{array}$} & \multirow{2}{*}{$\begin{array}{c}\text { Averso à } \\
\text { Exclusividade } \\
\text { (cluster } 3 \text { ) }\end{array}$} & \multicolumn{2}{|c|}{ ANOVA } \\
\hline & & & & $\mathrm{F}$ & Sig. \\
\hline Equidade & 5,645 & 3,933 & 5,716 & 137,46 & $<0,001$ \\
\hline Autenticidade & 6,044 & 4,257 & 5,900 & 138,53 & $<0,001$ \\
\hline Funcionalidade & 6,123 & 5,266 & 6,174 & 47,64 & $<0,001$ \\
\hline Localismo & 5,642 & 3,904 & 5,750 & 168,20 & $<0,001$ \\
\hline Exclusividade & 5,321 & 2,879 & 1,856 & 416,50 & $<0,001$ \\
\hline Orientação & Alta & Parcial & $\begin{array}{l}\text { Alta, exceto para } \\
\text { a Exclusividade }\end{array}$ & \multirow{2}{*}{\multicolumn{2}{|c|}{$\begin{array}{c}\text { Total de } \\
\text { Observações }\end{array}$}} \\
\hline Dimensões-chave & Todas & Funcionalidade & Exclusividade & & \\
\hline Observações por Cluster (N) & 136 & 149 & 176 & \multicolumn{2}{|c|}{461} \\
\hline
\end{tabular}

Nota. Base: 461 respondentes. Fonte: Dados da pesquisa.

Jung e Jin (2016) verificaram a existência de quatro perfis (clusters) de orientação ao consumo de slow fashion: (i) alto envolvimento; (ii) convencional; (iii) orientado à exclusividade; e (iv) baixo envolvimento. Os resultados deste estudo evidenciam perfis diferentes daqueles traçados pela pesquisa de 2016, como se observa na Tabela 5. A amostra foi agrupada em três clusters. O teste 
ANOVA revelou que as quatro dimensões da orientação ao consumo de slow fashion apresentaram significância estatística, indicando que todas elas são discriminantes na segmentação dos grupos. A opção por três clusters se deu pelo fato de todas as dimensões apresentarem significância estatística neste teste e por haver maior diferenciação entre clusters. Adicionalmente, realizou-se o teste de Tukey HSD para verificar diferenças estatísticas das médias das dimensões analisadas entre os clusters. Os resultados do teste de Tukey HSD são apresentados na Tabela 6.

\section{Tabela 6}

Comparação de médias entre os clusters de perfil de orientação ao consumo de slow fashion

\begin{tabular}{c|c|c|c|c|c|c|c|c|c|c|c}
\hline \multicolumn{2}{c|}{ Orientação ao SF } & \multicolumn{2}{|c|}{ Equidade } & \multicolumn{2}{c|}{ Autenticidade } & \multicolumn{2}{l|}{ Funcionalidade } & \multicolumn{2}{l|}{ Localismo } & \multicolumn{2}{c}{ Exclusividade } \\
\hline (A) & (B) & (A-B) & sig. & (A-B) & sig. & (A-B) & sig. & (A-B) & sig. & (A-B) & sig. \\
\hline Alta Ori. & O. Func. & 1,712 & 0,000 & 1,787 & 0,000 & 0,856 & 0,000 & 1,7438 & 0,000 & 2,442 & 0,000 \\
\hline A. Exclu. & O. Func. & 1,783 & 0,000 & 1,642 & 0,000 & 0,908 & 0,000 & 1,846 & 0,000 & $-1,023$ & 0,000 \\
\hline Alta Ori. & A. Exclu. & $-0,071$ & 0,827 & 0,144 & 0,438 & $-0,052$ & 0,873 & $-0,108$ & 0,604 & 3,465 & 0,000 \\
\hline
\end{tabular}

Nota. Base: 461 respondentes. Fonte: Dados da pesquisa.

De modo geral, os resultados deste estudo revelam que a amostra de respondentes cearenses se orienta ao consumo de slow fashion de formas distintas e encontram segmentadas em três clusters, que foram denominados da seguinte forma: (i) alta orientação; (ii) orientado à funcionalidade; e (iii) averso à exclusividade. Com base nos resultados apresentados na Tabela 5, verifica-se que o primeiro cluster (alta orientação) se diferencia do segundo (orientado à funcionalidade) em todas as dimensões (valor-p $=<0,001)$. Da mesma forma, o segundo cluster (orientado à funcionalidade) se diferencia do terceiro nas cinco dimensões analisadas (valor- $p=$ $<0,001$ ). Por fim, o primeiro (alta orientação) e o terceiro (averso à exclusividade) clusters diferenciamse apenas no que se refere à dimensão exclusividade (valor- $p=<0,001$ ), indicando que, de modo geral, os consumidores que compõem ambos os grupos apresentam elevada orientação ao consumo de slow fashion, com a diferença de que os consumidores do terceiro cluster não se engajam pela dimensão exclusividade, parecendo discordar radicalmente daquilo que nela é abordado, haja vista a baixa média dessa dimensão entre respondentes que compõem esse grupo.

Em relação às características gerais dos clusters, compreende-se que o primeiro conta com indivíduos que apresentaram médias elevadas em todos as dimensões da orientação ao consumo de slow fashion, denominado de perfil de "alta orientação", o que seria equivalente ao cluster "alto envolvimento" de Jung e Jin (2016). Entretanto, o artesanato e outras formas de produção local feita à mão, altamente valorizadas por consumidores deste perfil, bem como a preferência por recursos materiais locais (i.e. autenticidade) são dimensões que se destacam para os integrantes desse cluster (Aakko \& Koskennurmi-Sivonen, 2013; Cataldi et al, 2010; Clark, 2008; Fletcher, 2010; Jung \& Jin, 2014; Niinimäki \& Hassi, 2011; Pookulangara \& Shephard, 2013). Juntamente com esta dimensão, tem-se a funcionalidade, que também se comporta como a dimensão mais importante para os demais perfis deste estudo.

O segundo cluster sinaliza um perfil "orientado à funcionalidade", uma vez que os valores não são tão elevados quanto os do primeiro, mas, ao mesmo tempo, também não podem ser considerados baixos, uma vez que os respondentes apresentaram média elevada para a dimensão funcionalidade e médias moderadas para outras dimensões (i.e. equidade, autencididade e localismo) - este cluster se assemelha ao perfil "convencional" do estudo de Jung e Jin (2016). Visto que a proposta de moda sustentável slow fashion se baseia em coleções ecológicas e éticas (Antanavičintè \& Dobilaitè, 2015) e, dessa forma, em produtos sustentáveis, funcionais e duráveis (Cataldi et al., 2010; Clark, 2008), identificou-se que esse perfil tende mais para a dimensão funcionalidade. Esse achado sugere que tais consumidores se orientam mais para um estilo simples e funcional, por meio da valorização de roupas atemporais, versáteis, de alta durabilidade que vão além das tentências da moda, durando ao longo de várias temporadas (Jung \& Jin, 2016; Štefko \& Steffek, 2018; Watson \& Yin, 2013).

O terceiro cluster, por sua vez, foi denominado de perfil "averso à exclusividade". Aqueles que compõem este grupo apresentaram médias elevadas em todas as dimensões, exceto para exclusividade, ou seja, são indivíduos com elevada orientação ao consumo de slow fashion, mas que se afastam 
quando o consumo requer a escolha de peças raras, de edição limitada e que poucas pessoas têm (i.e. exclusividade) (Jung \& Jin, 2014). Este achado da pesquisa indica um perfil de orientação oposto ao "orientado à exclusividade" de Jung e Jin (2016), em que a apreciação por esse tipo de peças é alta. Isso ocorre uma vez que esta dimensão se apresenta como de menor importância para esse perfil da amostra de consumidores cearenses estudada. Paralelamente, esse grupo apresentou maiores médias em relação às dimensões equidade, funcionalidade e localismo dentre os perfis identificados, apresentando elevado engajamento em todas as outras dimensões do slow fashion.

\section{Fatores associados aos perfis de orientação ao consumo de slow fashion}

A fim de verificar os fatores associados aos perfis de orientação ao consumo de slow fashion, recorreuse ao método de análise de correspondência (ANACOR). Para a execução da ANACOR, faz-se necessário a realização do teste qui-quadrado, que deve apresentar significância estatística ao nível de $5 \%$, indicando associação satisfatória entre as variáveis (Fávero et al., 2009). Com base neste teste, verificou-se que os perfis não apresentaram associação satisfatória com as variáveis gênero e dependentes. No entanto, verificou-se que há associação entre os perfis de orientação ao consumo de slow fashion e as seguintes características do consumidor: localização, renda, faixa etária, orientação sexual, escolaridade, estado civil e ocupação.

Consoante à associação entre localização e orientação ao consumo de slow fashion, observa-se, de acordo com a Figura 2, que os indivíduos que vivem no interior do estado apresentam associação com um perfil de "alta orientação", enquanto aqueles que vivem na capital se associam com um perfil de "averso à exclusividade". Esse achado sugere que consumidores de regiões do interior do estado, onde a noção de artesanato como elemento da cultura local (Mazza et al., 2007) pode ser mais forte do que na capital, são mais propensos a se interessar por produtos de slow fashion. Corroborando com essa ideia, a visão de Fletcher e Grose (2012) sobre sentimentos de pertença a um lugar e a produção de pequena escala, mais artesanal, manifestarem aproximações com a noção de "local" dentro do consumo de slow fashion.

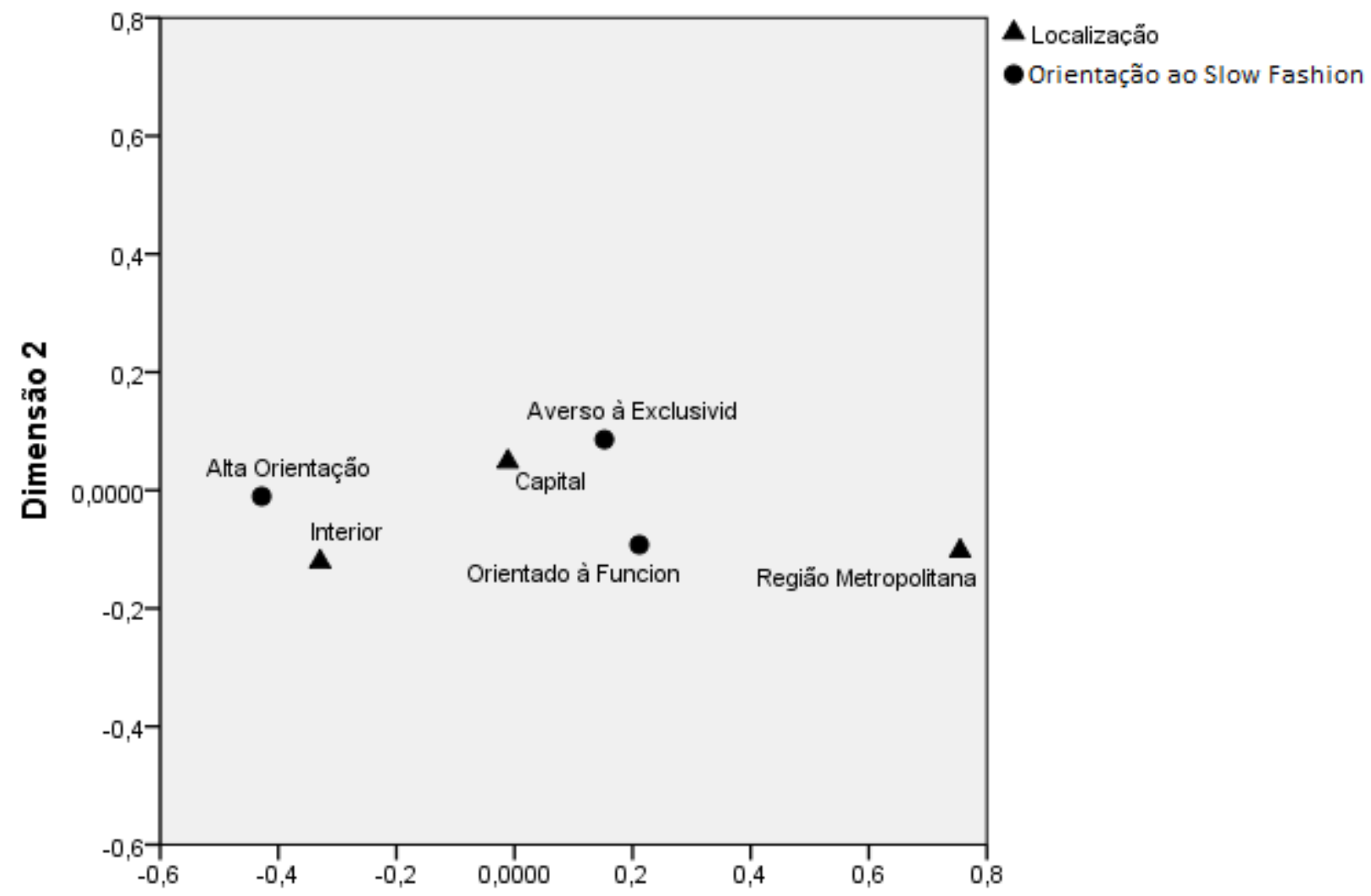

Dimensão 1

Figura 2. Mapa perceptual da associação entre as orientações ao consumo de slow fashion e a localização. 
No que diz respeito à associação entre renda e orientação ao consumo de slow fashion, a Figura 3 sugere que os indivíduos com menor renda (até $\mathrm{R} \$$ $2.000,00)$ tendem a apresentar um perfil de "alta orientação" e "orientado à funcionalidade". Este resultado pode indicar que, quanto menor a renda, maior a orientação para um tipo de consumo dentro da noção de slow fashion voltado à funcionalidade, ou seja, o consumidor tende a optar por peças mais versáteis e que podem ser utilizadas em diferentes contextos, otimizando, assim, seu consumo. No entanto, Štefko e Steffek (2018) afirmam que coleções de slow fashion apresentam preços mais altos, sugerindo que, para buscar maior exclusividade, maior deve ser a disposição a pagar um preço premium por produtos slow.

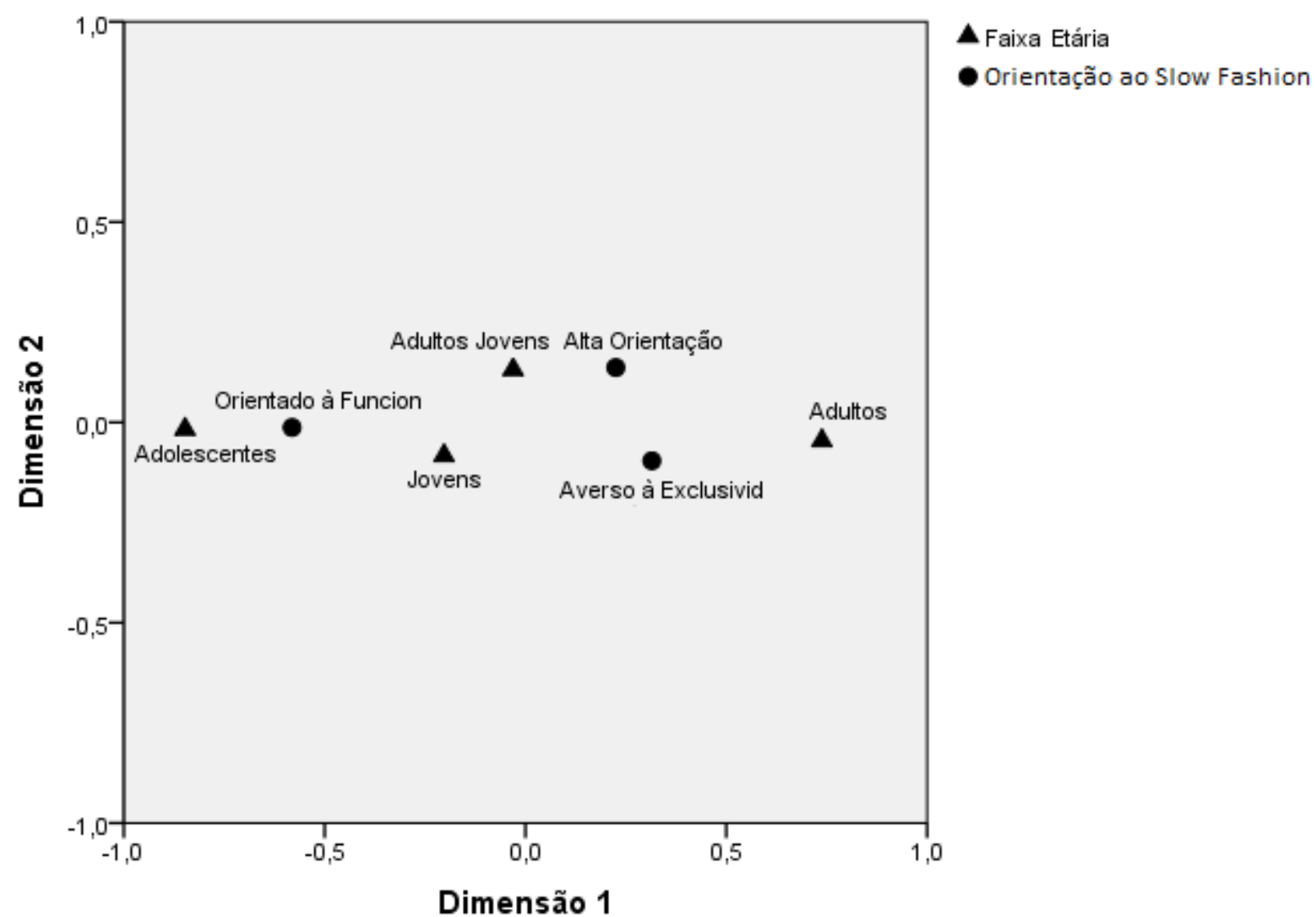

Figura 3. Mapa perceptual da associação entre as orientações ao consumo de slow fashion e a faixa etária.

Em relação à associação entre faixa etária e orientação ao consumo de slow fashion, verificou-se, por meio da Figura 4, que o público adolescente (14 a 17 anos) e jovem (18 a 24 anos) tende a um perfil "orientado à funcionalidade", enquanto os adultos (35 anos ou mais) tendem ao perfil "averso à exclusividade". Os adultos jovens ( 25 a 34 anos), por sua vez, apresentaram associação com um perfil de "alta orientação". Tal resultado sugere que grupos de adultos jovens são os mais orientados ao consumo de slow fashion no Ceará, de modo contrário ao que o estudo de Jung e Jin (2016b) evidencia. Nesse sentido, os potenciais consumidores norteamericanos de slow fashion apresentaram médias de idade superiores (i.e. 41 anos para o grupo de alto envolvimento, além de 54 e 41 anos para os grupos convencional e orientado à exclusividade, respectivamente) do que os potenciais consumidores cearenses (25 a 34 anos). Esse achado de pesquisa vai ao encontro do que foi afirmado por Bhardwaj e Fairhurst (2010) sobre consumidores mais velhos serem mais favoráveis ao slow fashion do que consumidores mais jovens. 


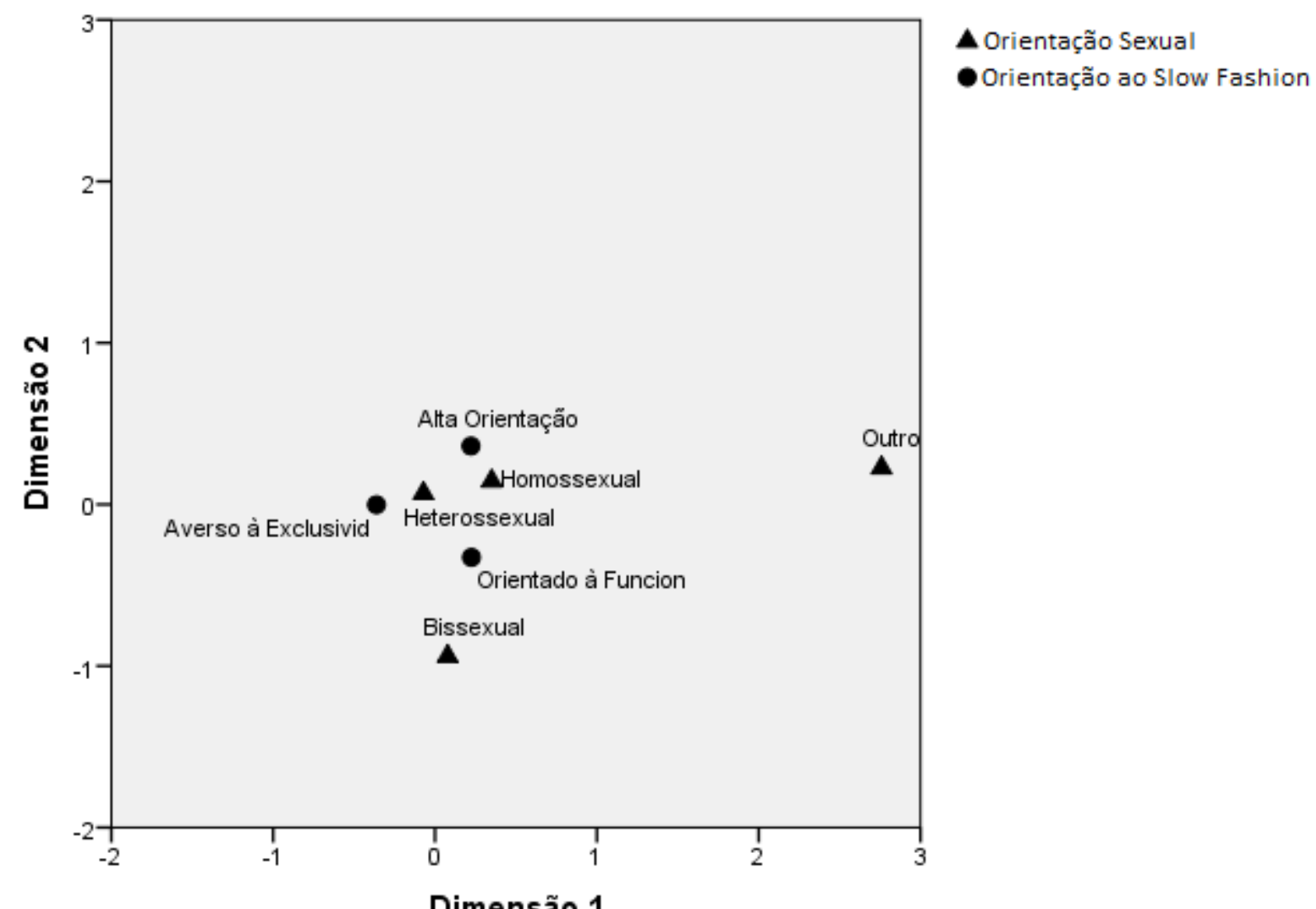

Dimensão 1

Figura 4. Mapa perceptual da associação entre as orientações ao consumo de slow fashion e a orientação sexual

No tocante à associação entre orientação sexual e orientação ao consumo de slow fashion, com base na Figura 5, compreende-se que os indivíduos que se declaram heterossexuais tendem a apresentar um perfil "averso à exclusividade". Pessoas que se reconhecem homossexuais apresentam associação com um perfil de "alta orientação", enquanto o público bissexual se associa com o perfil "orientado à funcionalidade". Diferentemente do estudo de Jung e Jin (2016b), este trabalho apresentou achados quanto à orientação sexual de potenciais consumidores de slow fashion, o que, para a amostra cearense pesquisada, revelou ser a maior orientação de consumidores LGBTs para esse tipo de consumo de moda sustentável. 


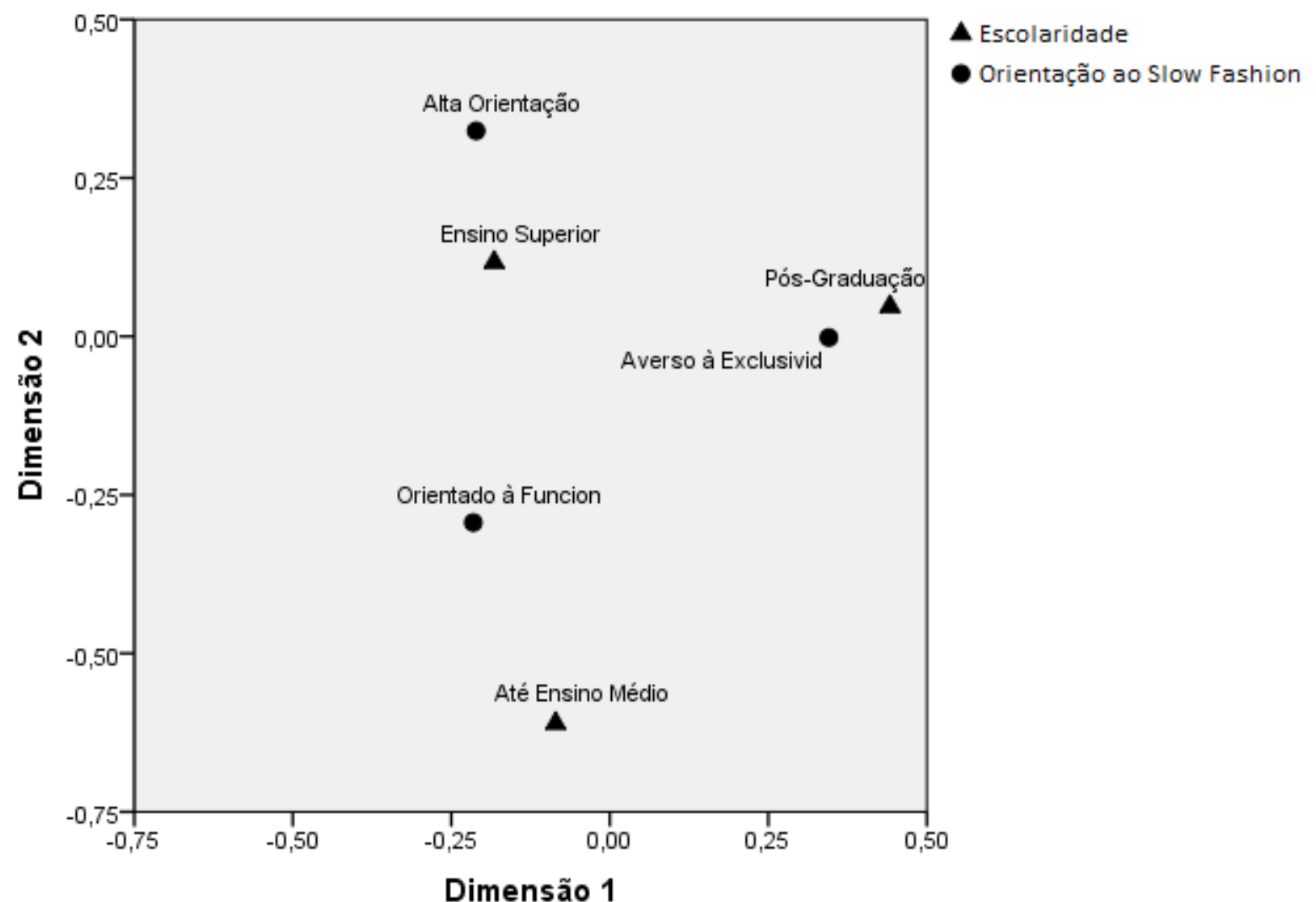

Figura 5. Mapa perceptual da associação entre as orientações ao consumo de slow fashion e a escolaridade.

No que se refere à associação entre escolaridade e orientação ao consumo de slow fashion, verifica-se, por meio da Figura 6, que os indivíduos com menor escolaridade (até ensino médio) apresentam um perfil "orientado à funcionalidade", portanto, inferior aos demais. Aqueles com ensino superior (cursando ou concluído) estão associados com "alta orientação" e os pós-graduados tendem a um perfil "averso à exclusividade". 


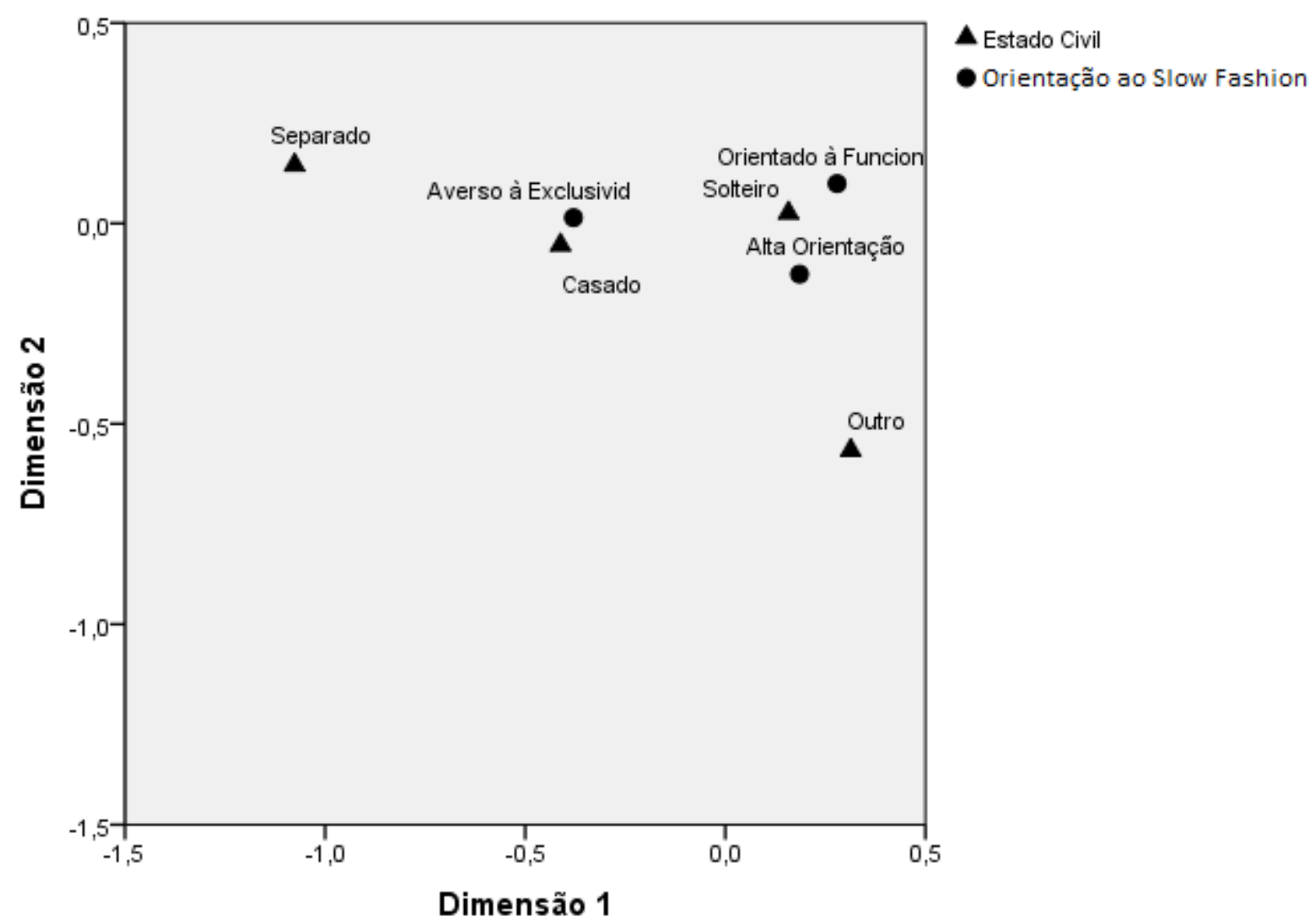

Figura 6. Mapa perceptual da associação entre as orientações ao consumo de slow fashion e o estado civil.

No que concerne à associação entre estado civil e tendem ao perfil "averso à exclusividade", enquanto orientação ao consumo de slow fashion, os os solteiros tendem aos perfis de "alta orientação" e resultados da Figura 7 revelam que pessoas casadas "orientado à funcionalidade". 


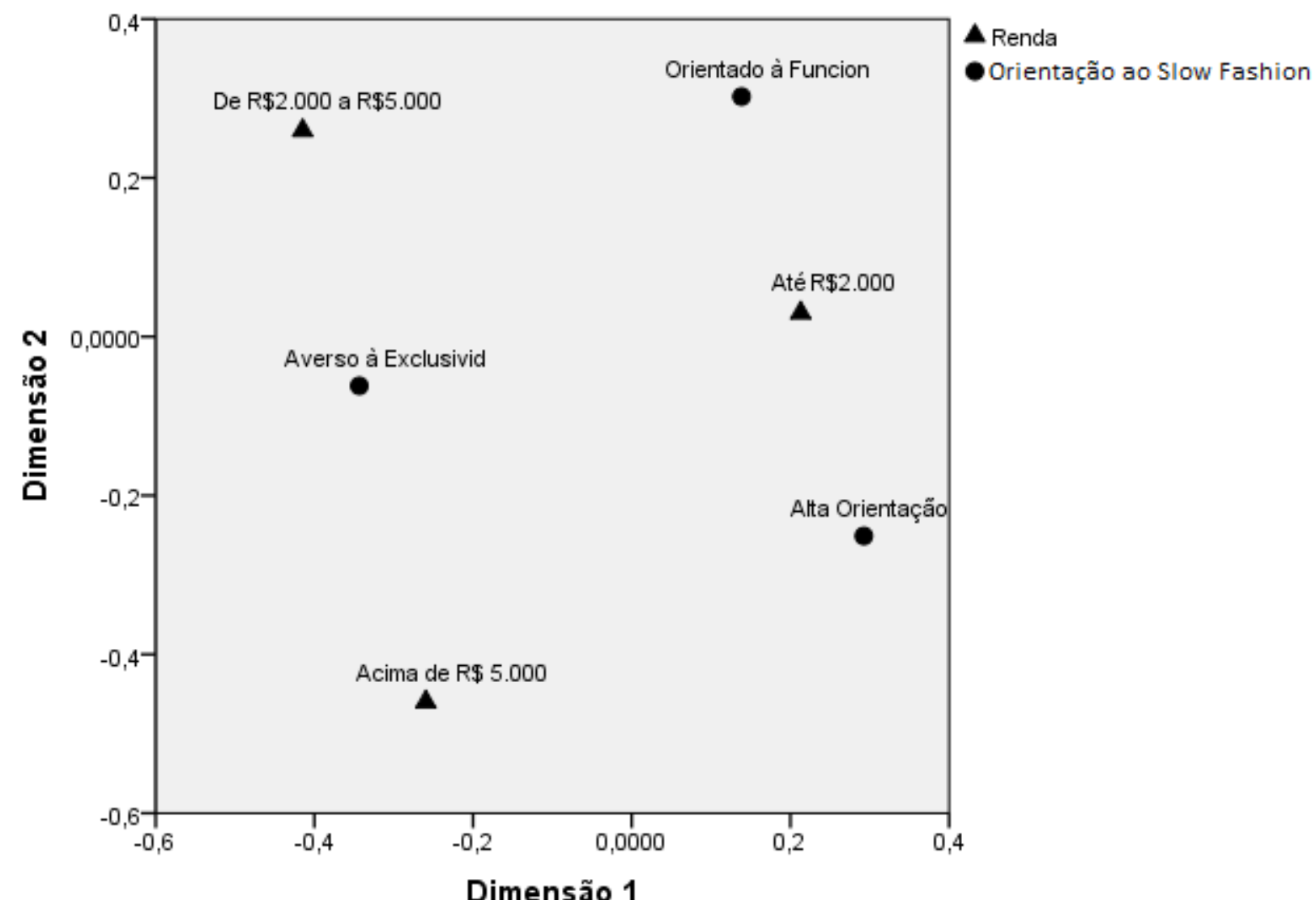

Figura 7. Mapa perceptual da associação entre as orientações ao consumo de slow fashion e a renda.

Por fim, de acordo com a Figura 8, no que tange à associação entre ocupação e orientação ao consumo de slow fashion, observa-se que profissionais ativos no mercado apresentam tanto um perfil de "alta orientação" quanto um "averso à exclusividade", e estudantes tendem ao perfil "orientado à funcionalidade". 


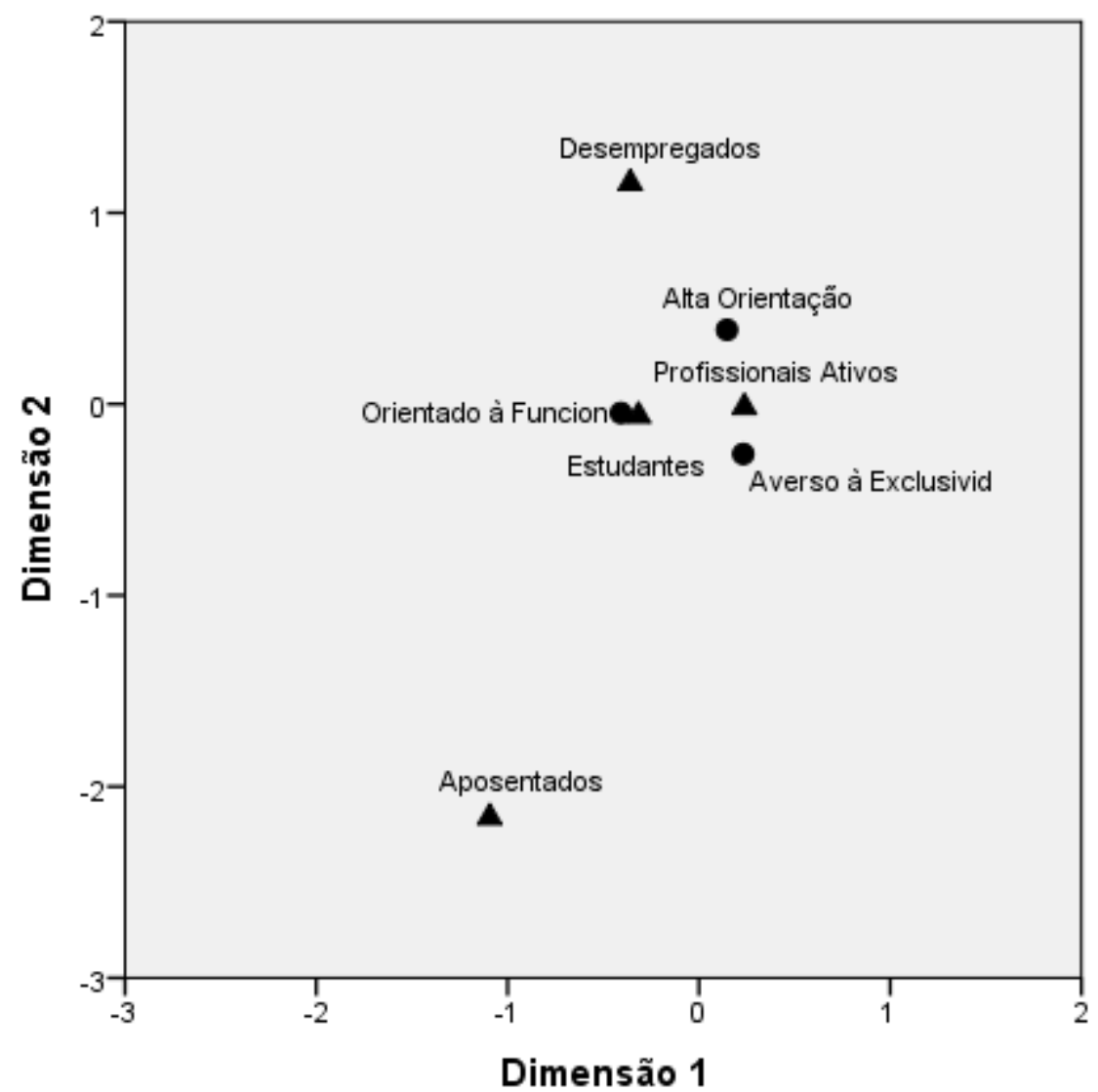

A Profissẩo

- Orientação ao Slow Fashion

Figura 8. Mapa perceptual da associação entre as orientações ao consumo de slow fashion e a profissão.

A Tabela 7 apresenta os principais fatores associados aos perfis de potenciais consumidores cearenses orientados ao consumo de slow fashion, resumindo os achados deste estudo.

Tabela 7

Perfis de consumidores cearenses orientados ao consumo de slow fashion

\begin{tabular}{|c|c|c|c|}
\hline & $\begin{array}{l}\text { Alta orientação } \\
\text { (cluster 1) }\end{array}$ & $\begin{array}{c}\text { Orientado à funcionalidade } \\
\text { (cluster } 2 \text { ) }\end{array}$ & $\begin{array}{c}\text { Averso à exclusividade } \\
\text { (cluster } 3 \text { ) }\end{array}$ \\
\hline Localização & Interior do Estado & - & Capital \\
\hline Renda & até $\mathrm{R} \$ 2.000,00$ & Até $\mathrm{R} \$ \mathbf{2} 2.000,00$ & - \\
\hline Faixa-etária & 25 a 34 anos & $\begin{array}{c}\text { Adolescentes (14 a } 17 \text { anos) } \\
\text { e Jovens (18 a } 24 \text { anos) }\end{array}$ & 35 anos ou mais \\
\hline Orientação sexual & Homossexuais & Bissexuais & Heterossexuais \\
\hline Estado civil & Solteiros & Solteiros & Casados \\
\hline Escolaridade & $\begin{array}{c}\text { Ensino superior } \\
\text { (cursando ou concluído) }\end{array}$ & Até ensino médio & Pós-graduação \\
\hline Ocupação & $\begin{array}{c}\text { Profissionais ativos no } \\
\text { mercado }\end{array}$ & Estudantes & $\begin{array}{c}\text { Profissionais ativos no } \\
\text { mercado }\end{array}$ \\
\hline Dimensões-chave & Todas & Funcionalidade & Exclusividade \\
\hline
\end{tabular}

Fonte: Dados da pesquisa.

Os achados da pesquisa possibilitaram a elaboração de cada cluster ou perfil orientado ao consumo de slow fashion segundo os fatores elencados na Tabela 7. Assim, cada perfil conta com particularidades que compõem as características dos diversos grupos de potenciais consumidores cearenses de moda lenta. Ressalta-se para este estudo que o fato desses grupos (e.g. adolescentes, jovens adultos, indivídios de maior ou menor renda) se associarem com o mesmo perfil, não significa que 
necessariamente eles acumulem essas características ao mesmo tempo.

O perfil de "alta orientação" (cluster 1) é composto por um segmento de consumidores que apresentam, pelo menos, uma das seguintes características: vivem no interior do estado; tem menor renda (até R\$2.000); com idade entre 25 e 34 anos; homossexuais; solteiros; com ensino superior (completo ou em andamento); ativos no mercado. De modo semelhante, o perfil "orientado à funcionalidade" (cluster 2) apresentou associação com as seguintes características: renda de até R\$2.000; presença de consumidores LGBTs (bissexuais); solteiros; mais jovens (14 a 24 anos); estudantes. Este perfil enfatiza a dimensão funcionalidade do slow fashion. Por sua vez, o perfil "averso à exclusividade" concentra consumidores com alguma(s) das seguintes características: vivem na capital; adultos (35 anos ou mais); heterossexuais; pessoas casadas; com pós-graduação; ativos no mercado. Apesar de aversos à dimensão exclusividade, estes consumidores apresentam elevada orientação ao consumo de slow fashion nas outras quatro dimensões.

Portanto, os achados da pesquisa sugerem que consumidores LGBTs (i.e. homossexuais e bissexuais) tendem a apresentar maior orientação ao consumo da moda lenta do que heterossexuais no Ceará. Tanto os indivídios que residem no interior do Estado (i.e. "alta orientação") quanto aqueles que residem na Capital (i.e. "averso à exclusividade") estão fortementemente associados com preocupações relativas à versatilidade e durabilidade de suas roupas (i.e. funcionalidade) (Clark, 2008; Jung \& Jin, 2014; 2016; Watson \& Yan, 2013). Isso se dá mesmo para aqueles aversos às peças mais exclusivas e de edição limitada (i.e. "averso à exclusividade"). Além disso, destacou-se para o primeiro cluster ("alta orientação") não só a valorização do artesanato e outras formas de produção feita à mão, bem como de materiais locais e consumo ético (i.e. autenticidade, localismo e equidade) (Jung \& Jin, 2014).

\section{Conclusões, Limitações e Pesquisas Futuras}

Esta pesquisa objetivou identificar perfis de orientação ao consumo de slow fashion, verificando os fatores associados aos diferentes perfis no Ceará. Para isso foi conduzida uma survey online utilizando a escala de Orientação do Consumidor para Slow fashion (COSF) (Jung \& Jin, 2014) a fim de medir a orientação a esse tipo de consumo neste Estado.

Os resultados indicam validade da escala no contexto desta pesquisa. Além disso, verificou-se a existência de três perfis de orientação a esse tipo de consumo: (i) alta orientação; (ii) orientado à funcionalidade; e (iii) averso à exclusividade. Ainda, observou-se que existe associação entre os diferentes perfis e as variáveis demográficas relacionadas à localização, renda, faixa etária, orientação sexual, escolaridade, estado civil e ocupação.

Dentre os achados deste estudo, observou-se que consumidores LGBTs (i.e. homossexuais e bissexuais) apresentaram maior orientação ao consumo de slow fashion do que heterossexuais. Além disso, esta pesquisa evidencia a relevância da dimensão funcionalidade para os três perfis formados, sugerindo que a orientação de consumidores cearenses a esse consumo envolve, sobretudo, a noção de versatilidade e durabilidade de vestuário. Esta pesquisa, ao propor identificar perfis orientados ao consumo de slow fashion no Ceará, levanta o debate sobre quem são os seus potenciais consumidores, uma vez que os resultados diferiram significativamente dos perfis encontrados por Jung e Jin (2016) quanto às características demográficas. Os consumidores potenciais no estudo anterior são adultos mais velhos (i.e. 45 anos) e apresentaram resultados para gênero, mas não para orientação sexual. No Brasil, grupos de consumidores de adultos jovens (i.e. 25 a 34 anos) e de LGBTs se destacaram. Neste estudo, vale ressaltar que a amostra pesquisada pode ser relevante para explicar o fenômeno investigado, isto é, a orientação ao consumo de slow fashion dos consumidores cearenses. Isso pode se dar em relação aos aspectos geográficos, segundo a localização desses potenciais consumidores (i.e. ser ou não ser cearense, ser ou não do interior) ou de aspectos demográficos (i.e. maior proporção de sexo feminino, ou de homossexuais). Este estudo apresenta como contribuição teórica a extensão do corpo de conhecimento sobre perfis de potenciais consumidores de slow fashion, se vinculando ao estudo de Jung e Jin (2016b) na tentativa de traçar tais perfis. No entanto, vai além ao expandir a amostra inicial adotada pelos referidos autores (i.e. de 221 respondentes para 461). Além disso, explora o tema moda lenta em outro contexto cultural e mercadológico, aplicando a pesquisa no Brasil, 
especificamente com consumidores cearenses. Assim, contribui para a área acadêmica ao validar a escala das autoras para um mercado diferente do norte-americano. As implicações gerenciais dizem respeito ao fornecimento de informações que possam contribuir para o planejamento mercadológico e posicionamento de marca eficiente e direcionado a esses potenciais consumidores. Nesse sentido, varejistas de slow fashion do Ceará podem explorar os fatores associados aos diferentes perfis, adequando seu mix de marketing a eles.

Como limitações de pesquisa, o fato da identificação dos perfis não considerar as características de cada grupo segundo a intenção de compra e a disposição a pagar por um produto slow fashion com preço premium. Recomenda-se que outras pesquisas possam envolver esses aspectos de análise. Além disso, outra limitação se dá pelo confronto com a literatura ser, sobretudo, em relação ao estudo de Jung e Jin (2016b), o único desenvolvido até o presente momento sobre grupos de potenciais consumidores de slow fashion. Uma vez que o grupo homossexual foi dividido igualmente nos 3 clusters, a despeito do resultado da Anacor, sugerimos que pesquisas futuras possam realizar uma análise mais aprofundada sobre esta relação. Outra limitação diz respeito ao se colocar o foco em consumidores cearenses, os perfis de orientação ao consumo de slow fashion e os respectivos fatores associados não refletirão o âmbito brasileiro, no entanto sinalizam tendências de consumo do contexto cearense. Estudos futuros podem comparar como potenciais consumidores de slow fashion de diversas regiões brasileiras estão orientados a esse tipo de consumo de moda sustentável. Atrelada a essa perspectiva, outras pesquisas podem buscar compreender como o consumo de slow fashion é difundido e adotado entre grupos de consumidores cearenses. Para tanto, sugere-como suporte teórico a teoria de difusão de inovações de Rogers (2003), visto que o slow fashion pode se enquadrar como uma tendência de inovação dentro da moda, a qual os consumidores de vestuário podem adotar. Assim, o "grau com que um indivíduo adota um produto inovador antes de outros membros de um sistema" (Rogers, 2003, p. 22) pode ser investigado com foco na moda lenta. Uma outra limitação está relacionada aos parâmetros estatísticos observados em alguns dados, como é o caso do Alfa de Cronbach calculado para a dimensão funcionalidade, que pode ser interpretado por alguns como um valor baixo. Em relação aos achados da pesquisa, destaca-se que, embora tenha-se buscado compor uma amostra heterogênea e que refletisse os cearenses como um todo, o processo de amostragem por conveniência pode ter sido um fator limitante.

Um questionamento que emerge deste estudo é sobre a indispensabilidade do atributo exclusividade para que o consumo de vestuário se caracterize como de slow fashion. Este estudo apresentou a formação de três perfis. Em um deles, a dimensão funcionalidade se sobressaiu, no entanto, apresentou a formação de um grupo avesso à dimensão exclusividade, contrastando com os resultados de Jung e Jin (2016b), onde há formação de um perfil que, na verdade, é orientado por esse atributo. Tendo em vista essas considerações, seriam os nordestinos mais orientados a um tipo de consumo slow menos exclusivo ou seria uma particularidade dos cearenses? Isso se daria pela força deste estado no mercado têxtil e de confecção, de artesanato local? Pesquisas futuras podem investigar a influência de valores e da cultura no consumo de slow fashion, explorar a relação entre a percepção de "local", de artesanato cearense e da percepção de slow fashion nesse Estado.

Ademais, dado o sugimento do grupo averso à exclusividade nesta pesquisa, estudos futuros podem buscar compreender como se dá relação entre a funcionalidade e a exclusividade dentro da lógica de consumo de slow fashion. A percepção de consumidores sobre o atributo exclusivo versus o funcional pode ser investigada. Seria o slow fashion um tipo de consumo funcional, autêntico, ético e local, que pode ser mais ou menos orientado à exclusividade? As implicações gerenciais dentro dessa perspectiva envolvem como empresas de slow fashion podem se utilizar de um posicionamento de marca mais voltado para um nicho que se aproximaria de produtos de luxo (i.e. mais orientado à exclusividade) ou à um mercado mais integrador de consumidores com menor renda, para que estes possam adquirir produtos slow menos exclusivos por preços mais acessíveis, o que poderia constituir um posicionamento de marca menos orientada à exclusividade.Sugere-se, ainda, que outros estudos possam adotar o construto atitude sustentável como background teórico, associando-o às orientações para esse tipo de consumo, visto que o slow fashion está intimamente ligado à noção de sustentabilidade no campo do consumo de moda (Henninger et al., 2016). Para além de importância do local, a noção de glocal. Pesquisas futuras podem estudar como as 
Ertekin, Z. O., \& Atik, D. (2015). Sustainable markets: motivating factors, barriers, and remedies for mobilization of slow fashion. Journal of Macromarketing, 35(1), 53-69.

Fávero, L. P., Belfiore, P., Silva, F. L., \& Chan, B. L. (2009). Análise de dados: modelagem multivariada para tomada de decisões. Rio de Janeiro: Campus.

Fletcher, K. \& Grose, L, (2012). Fashion \& Sustainability - Design for Change, London: Laurence King Publishing.

Fletcher, K. (2008). Sustainable Fashion \& Textiles: design journeys. Sterling, VA: Earthscan.

Fletcher, K. (2010). Slow fashion: an invitation for change. Fashion Practice: The Journal of Design, Creative Process \& the Fashion Industry, 2(2), 259266.

George, D., \& Mallery, P. (2003). SPSS for Windows step by step: a simple guide and reference (4th ed.). Boston: Allyn \& Bacon.

Hair Jr., J. F., Black, W. C., Babin, B. J., \& Anderson, R. E. (2009). Análise multivariada de dados (6th ed.). Porto Alegre: Bookman.

Hall, J. (2018). Digital Kimono: Fast Fashion, Slow Fashion? Fashion Theory, 22(3), 283-307.

Henninger, C. E., Alevizou, P. J., \& Oates, C. J. (2016). What is sustainable fashion? Journal of Fashion Marketing and Management: An International Journal, 20(4), 400-416.

Hofmeyr, D. P. (2020). Degrees of freedom and model selection for k-means clustering. Computational Statistics \& Data Analysis, 149, 1-14.

Hooper, D., Coughlan, J. \& Mullen, M. R. (2008). Structural Equation Modelling: guidelines for determining model fit. The Electronic Journal of Business Research Methods, 6(1), 53-60.

Instituto de Pesquisa e Estratégia Econômica do Ceará [IPECE]. (2017). Anuário estatístico do Ceará 2017. Recuperado em 25 abr. 2020, de http://www2.ipece.ce.gov.br/publicacoes/anuario/a nuario2017/index.htm
Johansson, E. (2010). Slow fashion - the answer for a sustainable fashion industry? Thesis, University of Boras, Suécia.

Joy, A., Sherry Jr, J. F., Venkatesh, A., Wang, J., \& Chan, R. (2012). Fast fashion, sustainability, and the ethical appeal of luxury brands. Fashion theory, 16(3), 273-295.

Jung, S. \& Jin, B. (2014). A theoretical investigation of slow fashion: sustainable future of the apparel industry. International Journal of Consumer Studies, 38(5), 510-519.

Jung, S., \& Jin, B. (2016a). Sustainable Development of Slow fashion Businesses: Customer Value Approach. Sustainability, 8(6), 1-15.

Jung, S., \& Jin, B. (2016b). From quantity to quality: understanding slow fashion consumers for sustainability and consumer education. International Journal of Consumer Studies, 40(4), 410-421.

Lee, D. A., \& Ahn, I. S. (2015). A study on slow fashion related to convergence design. Journal of the Korean Society of Costume, 65(2), 33-47.

Legere, A., \& Kang, J. (2020). The role of selfconcept in shaping sustainable consumption: A model of slow fashion. Journal of Cleaner Production, 120699. doi:10.1016/j.jclepro.2020.120699

Levy, M., \& Weitz, B. A. (2008). Retailing Management, 7th ed., McGraw-Hill Irwin, Boston, MA.

Lugoe, W. (2019, julho 5). Nordeste sustentável. O Povo, Mercado, p. 19.

Magno, L. (2015, dezembro 10). Jô de Paula: boa nova do handmade. Recuperado de https://marciatravessoni.com.br/blog/jo-de-paulaboa-nova-do-handmade/

Magno, L. (2019, dezembro 10). Destaque da moda no Ceará, Gabriela Fiuza faz a diferença apostando na slow fashion. Recuperado de https://marciatravessoni.com.br/moda/destaqueda-moda-no-ceara-gabriela-fiuza-faz-a-diferencaapostando-na-slow-fashion/ 
Magnuson B., Reimers, V., \& Chao F. (2017). Revisiting an old topic with a new approach: the case of ethical clothing. Journal of Fashion Marketing and Management: An International Journal, 21(3), 400418.

Mazza, A. C. A., Ipiranga, A. S. R., \& Freitas, A. A. F. de. (2007). O design, a arte e o artesanato deslocando o centro. Cadernos EBAPE.BR, 5(4), 01-11.

Mukendi, A., Davies, I., Glozer, S. and McDonagh, P. (2020), "Sustainable fashion: current and future research directions", European Journal of Marketing, Vol. ahead-of-print No. ahead-of-print. https://doi.org/10.1108/EJM-02-2019-0132Nielsen. (2019, abril 6).

Nielsen (2019). Brasileiros estão cada vez mais sustentáveis e conscientes. Recuperado de https://www.nielsen.com/br/pt/insights/article/201 9/brasileiros-estao-cada-vez-mais-sustentaveis-econscientes/

Niinimäki, K., \& Hassi, L. (2011). Emerging design strategies in sustainable production and consumption of textiles and clothing. Journal of Cleaner Production, 19(16), 1876-1888.

Overdiek, A. (2018). Opportunities for slow fashion retail in temporary stores. Journal of Fashion Marketing and Management: An International Journal, 22(1), 67-81.

Pessoa, J., \& Santos, R. (2016). Renda-se ao meu Ceará: um discurso através de técnicas de artesanato à construção do vestuário. In Anais, 12, Colóquio de Moda (pp. 1-12), São Paulo: Biblioteca Virtual da FAPESP.

Podsakoff, P. M., MacKenzie, S. B., Lee, J.-Y., \& Podsakoff, N. P. (2003). Common method biases in behavioral research: A critical review of the literature and recommended remedies. Journal of Applied Psychology, 88(5), 879-903.
Pookulangara, S., \& Shephard, A. (2013). Slow fashion movement - Understanding consumer perceptions: an exploratory study. Journal of Retailing and Consumer Services, 20(2), 200-206.

Quevedo, C. (2017, dezembro 10). Guia consciente: 10 marcas brasileiras de slow fashion. Recuperado de https://woomagazine.com.br/guiaconsciente-10-marcas-brasileiras-de-slow-fashion/

Ro, J. H., \& Kim, M. J. (2011). The characteristics and aesthetic values of slow fashion from a social viewpoint. Journal of the Korean Society of Clothing and Textiles, 35(11), 1386-1398.

Rogers, E. M. (2003). Diffusion of innovations (5a ed.). New York: Free Press.

Şener, T., Bişkin, F. \& Kđlđnç, N. (2019). Sustainable dressing: consumers' value perceptions towards slow fashion. Business Strategy and the Environment, 28(8), 1-10.

Štefko, R., \& Steffek, V. (2018). Key Issues in Slow fashion: Current Challenges and Future Perspectives. Sustainability, 10(7), 2270-2281.

Sutter, M. B., Polo, E. F., \& Maclennan, M. L. F. (2014). Atributos da imagem do país de origem como fonte de vantagem competitiva: estudo no segmento internacional da moda brasileira. Internext, 9(2), 7593.

Teixeira, E. B., Zamberlan, L., \& Rasia, P. C. (2009). Pesquisa em administração. Ijuí: Editora Unijuí.

Thomas, K. (2020). Cultures of sustainability in the fashion industry. Fashion Theory, 24(5), 715-742.

Watson, M. Z., \& Yan, R. (2013). An exploratory study of the decision processes of fast versus slow fashion consumers. Journal of Fashion Marketing and Management: An International Journal, 17(2), 141159. 


\title{
Sobre os autores:
}

Érica Maria Calíope Sobreira - Universidade Federal do Paraná - UFPR, Curitiba, PR (Brasil). Email: erica.mcs21@gmail.com Orcid id: https://orcid.org/0000-0002-7162-4676

Clayton Robson Moreira da Silva - Instituto Federal de Educação, Ciência e Tecnologia do Piauí - IFPI, Pedro II, PI (Brasil). Email: claytonrmsilva@gmail.com. Orcid id: https://orcid.org/0000-0003-0717-2713

Cláudia Buhamra Abreu Romero - Universidade Federal do Ceará - UFC, Fortaleza, CE (Brasil). Email: buhamra@ufc.br. Orcid id: https://orcid.org/0000-0002-5971-7693

\section{SLOW PROFILE: STUDY OF SLOW FASHION CONSUMPTION ORIENTATIONS}

\author{
Érica Maria Calíope Sobreira, Clayton Robson Moreira da Silva, Cláudia Buhamra Abreu Romero \\ Universidade Federal do Paraná - UFPR, Curitiba, PR (Brasil) \\ Instituto Federal de Educação, Ciência e Tecnologia do Piauí - IFPI, Pedro II, PI (Brasil) \\ Universidade Federal do Ceará - UFC, Fortaleza, CE (Brasil)
}

\section{ARTICLE DETAILS}

\section{Article history:}

Received: 21 December 2019

Accepted: 25 July 2020

Available online August: 01 th 2020

Double Blind Review System

Scientific Editor

Ilan Avrichir

\section{Key words}

Slow fashion

Comsumption Orientation

Consumer Profile

\begin{abstract}
Objective: To identify slow fashion consumption orientation profiles, verifying the factors associated with the different profiles.

Method: This is a survey with 461 clothing consumers in the state of Ceará. The data collection instrument was composed of questions related to the characterization of the respondent's profile, as well as a section focused on measuring slow fashion consumption orientations, using the scale developed by Jung and Jin (2014). To reach the research objective, statistical methods of descriptive analysis, confirmatory factor analysis (CFA), cluster analysis by k-means, and correspondence analysis were used.

Main Results: The results indicate the validity of the scale in the context of this research. In addition, three slow fashion consumption orientation profiles were observed: highly orientation, functionality oriented, and exclusivity adverse. Furthermore, it was observed that there is an association between different profiles and demographic variables related to location, income, age, sexual orientation, education, marital status, and occupation.

Relevance/originality: Slow fashion studies still lack information about who are its potential consumers and about their profiles. This study aims to fill this gap in the literature. This research is theoretically relevant once it studies slow fashion and its potential consumers in Brazil, and, from a managerial point of view, it is relevant because number of Brazilian brands following the slow fashion concept has been increasing.

Theoretical/methodological contributions: As a theoretical contribution, it extends the body of knowledge on profiles of potential slow fashion consumers.

Social/managerial contributions (opcional): The managerial implications concern the provision of information that can contribute to efficient and targeted marketing planning and brand positioning for these potential consumers.
\end{abstract}




\title{
SLOW PROFILE: ESTUDIO DE LAS ORIENTACIONES PARA EL CONSUMO DE SLOW FASHION
}

\author{
Érica Maria Calíope Sobreira, Clayton Robson Moreira da Silva, Cláudia Buhamra Abreu Romero \\ Universidade Federal do Paraná - UFPR, Curitiba, PR (Brasil) \\ Instituto Federal de Educação, Ciência e Tecnologia do Piauí - IFPI, Pedro II, PI (Brasil) \\ Universidade Federal do Ceará - UFC, Fortaleza, CE (Brasil)
}

\section{HISTORIA DEL ARTÍCULO}

Historia del Artículo:

Recibido: 21 de Diciembre de 2019

Aceptado: 25 de Julio de 2020

Disponible en línea: 01 de Agosto 2020

Double Blind Review System

Editor Científico

llan Avrichir

\section{Palabras-clave:}

Slow fashion

Orientaciones de Consumo

Perfil del Consumidor

\begin{abstract}
RESUMEN
Objetivo: Identificar perfiles de orientación de consumo de slow fashion, verificando los factores asociados con los diferentes perfiles.

Método: Esta es una investigación survey, que reúne una muestra de 461 consumidores de ropa en el estado de Ceará. El instrumento de recolección de datos tenía preguntas relacionadas con la caracterización del perfil del encuestado, así como una sección dedicada a medir la orientación del consumo de slow fashion, utilizando la escala desarrollada por Jung y Jin (2014). Para cumplir el objetivo de la investigación, se utilizaron métodos estadísticos de análisis descriptivo, análisis factorial confirmatorio (AFC), análisis de conglomerados por $k$-means y análisis de correspondencia (ANACOR).

Resultados principales: Los resultados indican la validez de la escala de orientación de consumo de slow fashion en el contexto de esta investigación. Además, había tres perfiles de orientación de consumo de slow fashion: alta orientación; orientado a la funcionalidad; y adverso a la exclusividad. Además, se observó que existe una asociación entre diferentes perfiles y variables demográficas relacionadas con la ubicación, ingresos, edad, orientación sexual, educación, estado civil y ocupación.

Relevancia/originalidad: Los estudios de moda lenta aún carecen de información sobre quiénes son sus consumidores potenciales y cuáles son sus perfiles. Este estudio tiene como objetivo llenar este vacío en la literatura. Esta investigación es teóricamente relevante para estudiar la moda lenta y sus consumidores potenciales en Brasil y, desde un punto de vista administrativo, para el creciente número de marcas brasileñas que siguen el concepto de moda lenta.

Contribuciones teóricas/metodológicas: Como contribución teórica, amplía el conjunto de conocimientos sobre los perfiles de potenciales consumidores de moda lenta.

Contribuciones sociales/gerenciales (opcional): Las implicaciones gerenciales se refieren a la provisión de información que puede contribuir a una planificación de marketing eficiente y dirigida y al posicionamiento de la marca para estos consumidores potenciales.
\end{abstract}

Como Citar:

Sobreira, É., Silva, C., \& Romero, C. (2020). Slow Profile: Estudo das Orientações ao Consumo de Slow Fashion. Internext, 15(3), 103-127. doi:http://dx.doi.org/10.18568/internext.v15i3.589 